\title{
DYNAMIC CONSUMPTION AND PORTFOLIO CHOICE WITH \\ STOCHASTIC VOLATILITY IN INCOMPLETE MARKETS
}

\author{
George Chacko \\ Luis M. Viceira \\ Working Paper 7377 \\ http://www.nber.org/papers/w7377 \\ NATIONAL BUREAU OF ECONOMIC RESEARCH \\ 1050 Massachusetts Avenue \\ Cambridge, MA 02138 \\ October 1999
}

\begin{abstract}
We want to thank John Campbell, Pascal Maenhout, Robert Merton, Rachel Pownall, Enrique Sentana, Raman Uppal and seminar participants at HBS, CEMFI, the NBER, the XVII Latin American Meeting of the Econometric Society and the 1999 Conference of the European Finance Association for their comments and suggestions. The views expressed herein are those of the authors and not necessarily those of the National Bureau of Economic Research.

(C) 1999 by George Chacko and Luis M. Viceira. All rights reserved. Short sections of text, not to exceed two paragraphs, may be quoted without explicit permission provided that full credit, including $\odot$ notice, is given to the source.
\end{abstract}


Dynamic Consumption and Portfolio Choice with

Stochastic Volatility in Incomplete Markets

George Chacko and Luis M. Viceira

NBER Working Paper No. 7377

October 1999

JEL No. G12

\begin{abstract}
This paper analyzes optimal portfolio choice and consumption with stochastic volatility in incomplete markets. Using the Duffie-Epstein (1992) formulation of recursive utility in continuous time, it shows that the optimal portfolio demand for stocks under stochastic volatility varies strongly with the investor's coefficient of relative risk aversion, but only slightly with her elasticity of intertemporal substitution; by contrast, optimal consumption relative to wealth depends on both preference parameters. This paper also shows that stochastic variation in volatility produces an optimal intertemporal hedging demand for stocks which is negative when changes in volatility are instantaneously negatively correlated with excess stock returns and investors have coefficients of relative risk aversion larger than one. The absolute size of this demand increases with the size of this correlation, and also with the persistence of shocks to volatility. An application to the US stock market shows that empirically this correlation is negative and large, which implies a negative hedging demand for stocks. This application also shows that only low frequency shocks to volatility exhibit enough persistence to generate sizable hedging demands by long-term, risk averse investors. A comparative statics exercise shows that the size of hedging demands is considerably more sensitive to changes in persistence than to changes in correlation.
\end{abstract}

George Chacko

Harvard University

Graduate School of Business Administration

Boston, MA 02163

gchacko@hbs.edu
Luis M. Viceira

Harvard University

Graduate School of Business Administration

Boston, MA 02163

and NBER

lviceira@hbs.edu 


\section{Introduction}

Time-varying volatility is perhaps one of the most salient features of asset returns. Bollerslev et al. (1992) documents ample empirical evidence that the conditional variance of stock returns is not constant over time. Stock return volatility appears to be serially correlated, and shocks to volatility are negatively correlated with unexpected returns. Changes in volatility are persistent (French, Schwert and Stambaugh 1987, Campbell and Hentschel 1992). Large negative returns tend to be associated with increases in volatility that persist over long periods of time. In addition, stock return volatility appears to be correlated across markets over the world (Engle, Ito and Lin 1990, Ang and Bekaert 1999).

While there is an abundant literature that explores the implications of changing volatility for asset pricing models, the implications for optimal dynamic portfolio choice have been largely ignored. ${ }^{1}$ This is surprising, because Merton (1969, 1971, 1973) has shown that time-varying investment opportunities imply optimal portfolio strategies for multi-period investors that differ from those of single-period investors. Portfolio strategies differ because multi-period investors demand risky assets not only for their risk premia, but also because they are appropriate instruments to hedge consumption against adverse changes in future investment opportunities, provided that shifts in investment opportunities are correlated with asset returns. Thus investors have an extra demand for risky assets that reflects intertemporal hedging.

There is only one instance in which we can safely ignore the hedging component of the demand for risky assets: When investors have unit relative risk aversion coef-

\footnotetext{
${ }^{1}$ An exception is concurrent work developed by Liu (1998).
} 
ficients. For these investors, the substitution and income effects on portfolio choice produced by changes in the investment opportunity set exactly cancel out, and intertemporal hedging demands are zero (Merton 1969, 1971, 1973). However, the literature on the equity premium finds that the size of this premium is too large to be consistent with a representative-investor model in which the investor has unit relative risk aversion (Campbell 1998, Campbell, Lo, and MacKinlay 1997 [Chapter 8], Cecchetti, Lam, and Mark 1994, Cochrane and Hansen 1992, Hansen and Jagannathan 1991, Kocherlakota 1996, Mehra and Prescott 1985).

For investors with risk-aversion coefficients different from one, hedging demands are not necessarily zero. Recent research has examined the quantitative importance of hedging demands in light of the observed predictable variation in the equity premium (Balduzzi and Lynch 1997, Barberis 1998, Brandt 1998, Brennan, Schwartz and Lagnado 1996, Campbell and Viceira 1999) and in interest rates (Brennan, Schwartz and Lagnado 1997, Campbell and Viceira 1998). This research finds that hedging demand should represent a large fraction of the total demand for risky assets. Viceira (1998) shows that intertemporal hedging is also important for investors subject to uninsurable labor income risk.

This paper investigates the optimal consumption and portfolio choice of longhorizon investors when there is predictable variation in return volatility. It derives analytic expressions for the optimal consumption and portfolio policies of an infinitehorizon investor who rebalances her portfolio continuously. It considers two scenarios. In one scenario, expected returns do not vary with volatility, while in a second scenario, expected returns are allowed to covary linearly with volatility. Using these theoretical results, the paper evaluates the empirical relevance of intertemporal hedg- 
ing demands with stochastic volatility for U.S. investors.

Solving for the optimal consumption and portfolio policies of a multi-period investor when volatility is stochastic or, in general, when investment opportunities are time-varying, is not a trivial exercise. Kim and Omberg (1996) and Liu (1998) solve analytically for the optimal portfolio rule of an investor who maximizes power utility over terminal wealth and faces either a time-varying equity premium or time-varying volatility, respectively. Unfortunately, when the consumption decision is also endogenous, closed form solutions for the optimal policies have not been developed except when markets are complete. Using the method of Cox and Huang (1989), Wachter (1998) shows that the problem of optimal consumption and portfolio choice with timevarying expected returns has a closed-form solution, provided that the state variable is instantaneously perfectly correlated with returns or, equivalently, that markets are complete. This paper extends this complete markets result to time-variation in volatility using a dynamic programming approach. Schroder and Skiadas (1997) and Fisher and Gilles (1998) also explore the implications of complete markets for optimal consumption and portfolio choice.

However, the assumption of perfect correlation is not empirically plausible in many instances. In particular, it is difficult to justify for the case of stochastic volatility given the empirical evidence on the matter. Therefore, in this paper we allow for imperfect correlation between stock returns and volatility. As a result, the problem we are left to solve is one in a setting of incomplete markets.

In order to solve this incomplete markets problem, we develop an approximation to the Bellman equation that is the continuous-time equivalent of that used in several discrete-time settings. Campbell and Viceira (1998, 1999) and Viceira (1998), build- 
ing on the work of Campbell (1993), have developed an analytic solution method that finds approximate solutions to the discrete-time problem when consumption is endogenous. Their solution methodology does not require markets to be complete. They replace the Euler equations of the problem and the intertemporal budget constraint with log-linear Taylor expansions and use the method of undetermined coefficients to find closed-form solutions for the approximate problem. They apply this method to solve for the optimal policies when investors face a time varying equity-premium (Campbell and Viceira, 1999), stochastic interest rates (Campbell and Viceira, 1998) or uninsurable labor income risk (Viceira, 1998). This paper develops a continuoustime counterpart to the Campbell-Viceira solution method to solve for the optimal consumption and portfolio policies when volatility is stochastic. By working in continuous time we are able to provide an exact solution to the problem when the investor's elasticity of intertemporal substitution is unity - though her relative risk aversion coefficient need not be equal to one. In all other cases, the solution is approximate, but it requires only one approximation on one of the terms of the Bellman equation. This approximation technique can be viewed as a particular class of the perturbation methods described in Judd (1998).

This paper, like the Campbell-Viceira papers, assumes that preferences are given by Epstein-Zin-Weil recursive utility, a generalization of power utility that separates relative risk aversion from the elasticity of intertemporal substitution of consumptiontwo conceptually different objects, which under power utility are inextricably linked by a single parameter, one being the inverse of the other. Schroder and Skiadas (1997) and Fisher and Gilles (1998) also assume recursive preferences.

We find that, when expected excess returns are constant and all time-variation in 
the Sharpe ratio of the risky asset is in the denominator, optimal portfolio demand for stocks is proportional to precision, the inverse of stock volatility. When expected returns covary linearly with volatility, optimal portfolio demand is an affine function of precision. We also find that stochastic volatility produces an optimal intertemporal hedging demand for stocks. The sign of this hedging component of portfolio demand is the same as the sign of the instantaneous correlation between changes in volatility and excess stock returns. The absolute size of this demand increases with the size of this correlation, and also with the persistence of shocks to volatility. An empirical calibration using monthly U.S. stock returns from 1926 to 1997, and annual stock returns from 1871 to 1997 shows that persistence in shocks to volatility is considerably more important than correlation in determining the size of hedging demands. ${ }^{2}$

The paper is organized as follows. Section 2 states the dynamic optimization problem, Section 3 presents an exact solution to the problem when the investor has unit elasticity of intertemporal substitution - though her coefficient of relative risk aversion can take any value - and Section 4 explains the continuous-time approximate solution method that allows us to solve the problem when the elasticity of intertemporal substitution differs from unity. Section 4 also states the solution implied by the method. Section 5 explores the solution to the problem when expected excess returns covary with volatility. Section 6 describes how to apply Spectral GMM (Chacko and Viceira 1998, Singleton 1997) to estimate the parameters of the stochastic volatility

\footnotetext{
${ }^{2}$ This result is helpful to understand the numerical findings in Ang and Bekaert (1999) for international portfolio diversification. Using a regime switching model to describe time-variation in cross-country return correlations from 1970 to 1997, they estimate little persistence in shocks to these correlations and they find that hedging demands generated by time-variation in these correlations are small. Based on our results, we suspect that their first result explains the second.
} 
model. Section 7 calibrates the model to monthly U.S. stock market data and explores the empirical implications of stochastic volatility for portfolio choice. Finally, Section 8 concludes.

\section{The Intertemporal Consumption and Portfolio Choice Problem}

We assume that wealth consists of only tradable assets. Moreover, to keep the analysis simple, we assume in this paper that there are only two tradable assets. One of the assets is riskless, with instantaneous return $d B_{t} / B_{t}=r d t$. The second asset is risky, with instantaneous total return dynamics given by

$$
\frac{d S_{t}}{S_{t}}=\mu+\sqrt{v_{t}} d W_{s}
$$

where $v_{t}$ is the time-varying instantaneous variance of the return on the risky asset, and $S_{t}$ is the value of a fund fully invested in the asset that reinvests all dividends.

Thus, the expected excess return on the risky asset over the riskless asset $(\mu-r)$ is constant over time. However, the conditional variance of the risky asset return varies stochastically over time, and this induces time variation in investment opportunities. We assume the following dynamics for the inverse of this variance:

$$
d y_{t}=\kappa\left(\theta-y_{t}\right) d t+\sigma \sqrt{y_{t}} d W_{y}
$$

where $y_{t}=1 / v_{t}$ is the precision of the risky asset return process. Precision follows a mean-reverting process with long-term mean equal to $\theta$ and reversion parameter 
$\kappa>0 .^{3}$ This parameterization of the process for precision implies a process for $v_{t}$ that can capture the main stylized facts about volatility in asset markets. To see this, we can apply Ito's Lemma to (2) and find the following stochastic differential equation for $v_{t}$ :

$$
\frac{d v_{t}}{v_{t}}=\kappa_{v}\left(\theta_{v}-v_{t}\right) d t-\sigma \sqrt{v_{t}} d W_{y},
$$

where $\theta_{v}=\left(\theta-\sigma^{2} / \kappa\right)^{-1}$ and $\kappa_{v}=\kappa / \theta_{v}$. Equation (3) implies that volatility is meanreverting and that proportional changes in volatility are more pronounced in times of high volatility than in times of low volatility.

We also assume that unexpected returns on the asset are instantaneously correlated with innovations in precision. This instantaneous correlation is given by $\rho$. Therefore, proportional changes in volatility and returns are correlated, with instantaneous correlation

$$
\operatorname{Corr}_{t}\left(\frac{d v_{t}}{v_{t}}, \frac{d S_{t}}{S_{t}}\right)=-\rho .
$$

Investor's preferences are described by a recursive utility function. Recursive utility is a generalization of the standard, time-separable power utility model that separates relative risk aversion from the elasticity of intertemporal substitution of consumption. ${ }^{4}$ Epstein and Zin $(1989,1991)$ derive a parameterization of recursive utility in a discrete-time setting, while Duffie and Epstein (1992a, 1992b) and Fisher and Gilles (1998) offer a continuous-time analogue. We adopt the Duffie and Epstein

\footnotetext{
${ }^{3}$ In order to satisfy standard integrability conditions, we assume that $2 \kappa \theta>\sigma^{2}$.

${ }^{4}$ Power utility restricts the elasticity of intertemporal substitution parameter to be the inverse of the relative risk aversion coefficient, while in fact these two parameters need not be related to one another.
} 
(1992b) parameterization:

$$
J=\mathrm{E}_{t}\left[\int_{t}^{\infty} \mathrm{f}\left(C_{s}, J_{s}\right) d s\right],
$$

where $\mathrm{f}\left(C_{s}, J_{s}\right)$ is a normalized aggregator of current consumption and continuation utility that takes the form

$$
\mathrm{f}(C, J)=\frac{\beta}{1-\frac{1}{\psi}}(1-\gamma) J\left[\left(\frac{C}{((1-\gamma) J)^{\frac{1}{1-\gamma}}}\right)^{1-\frac{1}{\psi}}-1\right],
$$

$\beta>0$ is the rate of time preference, $\gamma>0$ is the coefficient of relative risk aversion and $\psi>0$ is the elasticity of intertemporal substitution. Power utility obtains from (5) by setting $\psi=1 / \gamma$.

The normalized aggregator $\mathrm{f}\left(C_{s}, J_{s}\right)$ takes the following form when $\psi \rightarrow 1$ :

$$
\mathrm{f}(C, J)=\beta(1-\gamma) J\left[\log (C)-\frac{1}{1-\gamma} \log ((1-\gamma) J)\right] .
$$

The investor maximizes (4) subject to the intertemporal budget constraint

$$
d X_{t}=\left[\pi_{t}(\mu-r) X_{t}+r X_{t}-C_{t}\right] d t+\pi_{t} X_{t} \sqrt{v_{t}} d W_{s},
$$

where $X_{t}$ represents the investor's wealth, $\pi_{t}$ is the fraction of wealth invested in the risky asset and $C_{t}$ represents the investor's instantaneous consumption.

\section{An Exact Solution with Unit Elasticity of In- tertemporal Substitution}

Merton $(1969,1971,1973)$ has shown that the optimization problem (4)-(7) has an exact solution when the investor has $\log$ utility $(\gamma=\psi \equiv 1)$. In this case, it is 
optimal for the investor to behave myopically and ignore time variation in investment opportunities, and the dynamic problem essentially reduces to a static problem. For all other investors, however, intertemporal considerations matter and the dynamic problem does not reduce to a static problem.

Giovannini and Weil (1989) have shown - through an analysis of the Euler equations of the problem in discrete time that, for investors with unit elasticity of intertemporal substitution, it is optimal to behave myopically regarding the consumption decision, but that intertemporal considerations still enter their portfolio decision. Hence the $\psi=1$ case, though special, is very useful to understand the effects of time-varying investment opportunities on portfolio choice. ${ }^{5}$

Unfortunately, Giovannini and Weil do not pursue this issue further and they do not explicitly characterize the optimal portfolio rule. In this section we tackle this issue and derive an exact analytic solution that allows us to fully characterize portfolio choice under time-varying investment opportunities. ${ }^{6}$ The next section presents an approximate analytic solution for the general case in which $\psi$ is not restricted to one.

The optimization problem given by (4)-(7) has one state variable, the precision of the risky asset return or, equivalently, the volatility of the risky asset return.

\footnotetext{
${ }^{5}$ This special case ignores the effects of $\psi$ on portfolio choice. However, sections 4 and 6 below show that $\psi$, while important for the consumption decision, has only an indirect effect on portfolio choice.

${ }^{6}$ Campbell and Viceira $(1998,1999)$ do explore this issue further in a discrete-time setting and derive an analytical expresion for the optimal portfolio rule. However, their solution is only approximate, because it is based on an approximation to the log return on wealth. In continuous time, however, we can derive an exact expression for the log return on wealth which is linear in portfolio shares.
} 
Therefore, the value function of the problem $(J)$ depends on financial wealth $\left(X_{t}\right)$ and this state variable.

The Bellman equation for this problem is

$$
\begin{aligned}
0= & \sup _{\pi, C}\left\{\mathrm{f}\left(C_{s}, J_{s}\right)+\left[\pi(\mu-r) X_{t}+r X_{t}-C_{t}\right] J_{X}+\frac{1}{2} \pi^{2} X_{t}^{2} v_{t} J_{X X}+\kappa\left(\theta-y_{t}\right) J_{y}\right. \\
& \left.+\frac{1}{2} \sigma^{2} y_{t} J_{y y}+\rho \sigma \pi_{t} X_{t} J_{X y}\right\}
\end{aligned}
$$

where $\mathrm{f}(C, J)$ is given in (6) and subscripts on $J$ denote partial derivatives.

The first-order conditions for this equation are

$$
\begin{aligned}
C_{t} & =J_{X}^{-\psi}[(1-\gamma) J]^{\frac{1-\gamma \psi}{1-\gamma}} \beta^{\psi} \\
\pi_{t} & =-\left(\frac{J_{X}}{X_{t} J_{X X}}\right)\left(\frac{\mu-r}{v_{t}}\right)-\left(\frac{J_{X y}}{X_{t} J_{X X}}\right)\left(\frac{\rho \sigma}{v_{t}}\right) .
\end{aligned}
$$

Equation (9) results from the envelope condition, $\mathrm{f}_{C}=J_{X}$, from which the optimal consumption rule obtains once the value function is known. Equation (10) shows that the optimal portfolio share in the risky asset has two components. The first one is proportional to the risk premium times the inverse of the coefficient of relative risk aversion in the indirect utility function. This is the optimal demand for risky assets we find in single-period models, or in multi-period models with constant investment opportunities. For this reason it is called "myopic demand." The second component is Merton's intertemporal hedging demand. It depends on instantaneous rates of change of the value function, the instantaneous variance of the state variable, and the instantaneous correlation between changes in the state variable and the risky asset.

By inspection of (10), it is immediately seen that the hedging component of portfolio demand is non-zero unless $\sigma=0$ (constant investment opportunities), $\rho=0$ 
(no hedging value in risky asset), or $J_{X y}=0$. This last equality obtains when $\gamma=1$ (Merton 1969, 1971, 1973, Giovannini and Weil 1989). Note, however, that equations (9) and (10) do not represent a complete solution to the model until we solve for $J\left(X_{t}, y_{t}\right)$.

Substituting the first-order conditions into (8) and rearranging gives the Bellman equation:

$$
\begin{aligned}
0= & \mathrm{f}(C(J), J)-J_{X} C(J)-\frac{1}{2} \frac{\left(J_{X}\right)^{2}}{J_{X X}}(\mu-r)^{2} y_{t}-\frac{J_{X} J_{X y}}{J_{X X}} \rho \sigma(\mu-r) y_{t} \\
& +J_{X} X_{t} r-\frac{1}{2} \frac{\left(J_{X y}\right)^{2}}{J_{X X}} \rho^{2} \sigma^{2} y_{t}+J_{y} \kappa\left(\theta-y_{t}\right)+\frac{1}{2} J_{y y} \sigma^{2} y_{t},
\end{aligned}
$$

where $C(J)$ denotes the expression for consumption resulting from (9).

We now guess a solution of the form $J\left(X_{t}, y_{t}\right)=I\left(y_{t}\right) X_{t}^{1-\gamma} /(1-\gamma)$. Substituting this solution into the Bellman equation and simplifying yields the following ordinary differential equation (ODE):

$$
\begin{aligned}
0= & \left(\log \beta-\frac{\gamma}{1-\gamma} \log (1-\gamma)\right) \beta I-\frac{1}{1-\gamma} \beta I \log I-\beta I+\frac{(\mu-r)^{2}}{2 \gamma} I y_{t}+r I \\
& +\frac{\rho \sigma(\mu-r)}{\gamma} I_{y} y_{t}+\frac{\rho^{2} \sigma^{2}}{2 \gamma} \frac{\left(I_{y}\right)^{2}}{I} y_{t}+\frac{1}{1-\gamma} I_{y} \kappa\left(\theta-y_{t}\right)+\frac{\sigma^{2}}{2(1-\gamma)} I_{y y} y_{t} .
\end{aligned}
$$

This ODE has a solution of the form $I=\exp \left\{A y_{t}+B\right\}$ that leads to two algebraic equations for $A$ and $B$,

$$
\begin{aligned}
a A^{2}+b A+c & =0, \\
(1-\gamma)(\beta \log \beta+r-\beta)-\beta \gamma \log (1-\gamma)-\beta B+\kappa \theta A & =0,
\end{aligned}
$$

where

$$
a=\frac{\sigma^{2}}{2 \gamma(1-\gamma)}\left[\gamma\left(1-\rho^{2}\right)+\rho^{2}\right]
$$




$$
\begin{aligned}
b & =\frac{\rho \sigma(\mu-r)}{\gamma}-\frac{\beta+\kappa}{1-\gamma}, \\
c & =\frac{(\mu-r)^{2}}{2 \gamma} .
\end{aligned}
$$

The first equation is a quadratic equation in $A$, and the second equation is linear in $B$ given $A$. For general parameter values the equation for $A$ has two roots. These roots are always real provided that $\gamma>1$. From standard theory on quadratic equations, the product of the roots is equal to $c / a$. When $\gamma>1$, this ratio is always negative so that the roots have opposite signs. It is easy to check that $J\left(y_{t} ; A>0, \gamma>1\right)<$ $J\left(y_{t} ; A<0, \gamma>1\right)$ for all $y_{t}$, so that only the negative root maximizes the value function. ${ }^{7}$ This root is obtained by selecting the positive root of the discriminant of the quadratic equation. Therefore, $A<0$ when $\gamma>1$.

When $\gamma<1$, the roots are real - and a solution to the problem exists - if and only if

$$
\left(\frac{1-\gamma}{\gamma} \frac{\sigma(\mu-r)}{\beta+\kappa}\right)\left(2 \rho+\frac{\sigma(\mu-r)}{\beta+\kappa}\right)<1 .
$$

This condition implies that both roots of the quadratic equation are positive. In this case the largest root - again, the root associated with the positive root of the discriminant - maximizes the value function. Therefore, $A>0$ when $\gamma<1$.

The following two propositions state the solution:

Proposition 1 The indirect utility function, $J\left(X_{t}, y_{t}\right) \equiv J\left(X_{t}, 1 / v_{t}\right)$ is given by

$$
J\left(X_{t}, \frac{1}{v_{t}}\right)=\exp \left\{\frac{A}{v_{t}}+B\right\} \frac{X_{t}^{1-\gamma}}{1-\gamma},
$$

\footnotetext{
${ }^{7}$ Note that the equation for $B$ implies that $\partial B / \partial A>0$.
} 
where $A$ is the solution associated to the positive root of the discriminant of the quadratic equation (13), and B is the solution to the linear equation (14). Coefficient A satisfies $A /(1-\gamma)>0$.

Proof. The proof for this proposition follows immediately from (12) and the ensuing discussion, using that $y_{t}=1 / v_{t}$.

Substituting the solution for the indirect utility function given in Proposition 1 into (9) and (10), we can solve for the optimal policies:

Proposition 2 The optimal consumption and portfolio rules implied by Proposition 1 are

$$
\frac{C_{t}}{X_{t}}=\beta
$$

and

$$
\pi_{t}=\frac{\mu-r}{\gamma v_{t}}+\frac{\rho \sigma}{\gamma} \cdot A \cdot \frac{1}{v_{t}}
$$

Proof. The proof for this proposition follows immediately from Proposition 1 and (9)-(10), using $y_{t}=1 / v_{t}$.

Proposition 2 shows that when $\psi=1$, the optimal log consumption-wealth ratio is invariant to changes in volatility and it is equal to the rate of time preference. For an investor with unit elasticity of intertemporal substitution, the income and substitution effects on consumption produced by a change in the investment opportunity set exactly cancel out, and it is optimal for her to consume a fixed fraction of her wealth each period. For this reason this consumption policy is termed "myopic" in the asset allocation literature. By contrast, the optimal portfolio rule changes with volatility and includes a hedging term. 
The optimal portfolio demand for the risky asset has two components. The first one is the myopic demand, that depends only on the risk premium multiplied by the inverse of the relative risk aversion coefficient and current volatility. The second component is the intertemporal hedging demand. The sign of this demand depends on the sign of the correlation between unexpected returns and changes in volatility $(-\rho)$ and the sign of $A$. Proposition 2 shows that a negative correlation implies a negative hedging demand for investors with $\gamma>1$, and a positive hedging demand for investors with $\gamma<1$. Investors who are more risk averse than a logarithmic investor have a negative hedging demand for the risky asset because it lacks hedging properties against an increase in volatility: A negative correlation implies that the risky asset tends to do worse in those states of the world in which uncertainty is high.

The absolute size of the hedging demand for the risky asset is increasing in the persistence of shocks to return volatility when $\gamma>1$. To see this, note that $\partial A / \partial \kappa>$ 0. ${ }^{8}$ Since $A<0$ when $\gamma>1$, an increase in persistence (a decrease in $\kappa$ ) increases the absolute value of $A$ and hence the absolute value of the hedging component of $\pi_{t}$. If shocks to return volatility are highly persistent, the risky asset becomes a more valuable hedging instrument.

Coefficient $A$ is zero when the expected excess return on the risky asset is also zero. Therefore, when $\mu-r=0$ both the myopic component and the intertemporal component of the demand for the risky asset are zero. If the expected excess return on the risky asset is zero, any amount of risk taking is uncompensated, and it is optimal for the investor to simply pull out of the risky asset and to invest only on the riskless asset, hence eliminating all uncertainty about future consumption.

\footnotetext{
${ }^{8} \partial A / \partial \kappa>0$ is proportional to $A /(1-\gamma)$ and Proposition 1 shows that $A /(1-\gamma)>0$.
} 
Finally, another property of the solution is that the ratio of hedging demand to myopic demand is independent of the level of volatility. Therefore, the hedging component of demand is always a constant fraction of the total portfolio demand, no matter what the level of the state variable is. This is so because returns are instantaneously correlated with proportional changes in volatility rather than with absolute changes in volatility.

\section{Approximate General Solution}

Having analyzed the special case $\psi=1$ we can now address the general case that does not restrict the investor's willingness to substitute consumption intertemporally. In this case, both optimal portfolio choice and consumption will react to changes in volatility.

When $\psi$ is not restricted to one, we obtain the following ODE after plugging (5) into the Bellman equation, (11), and guessing that $J\left(X_{t}, y_{t}\right)=I\left(y_{t}\right) X_{t}^{1-\gamma} /(1-\gamma)$ :

$$
\begin{aligned}
0= & -\frac{1}{1-\psi} \beta^{\psi} I^{1+\frac{1-\psi}{1-\gamma}}+\frac{\psi}{1-\psi} \beta I+\frac{(\mu-r)^{2}}{2 \gamma} I y_{t}+\frac{\rho \sigma(\mu-r)}{\gamma} I_{y} y_{t}+r I \\
& +\frac{\rho^{2} \sigma^{2}}{2 \gamma} \frac{\left(I_{y}\right)^{2}}{I_{t}} y_{t}+\frac{1}{1-\gamma} I_{y} \kappa\left(\theta-y_{t}\right)+\frac{\sigma^{2}}{2(1-\gamma)} I_{y y} y_{t} .
\end{aligned}
$$

We can further simplify this equation by making the transformation $I=H^{-\frac{1-\gamma}{1-\psi}}$, which gives the following non-homogeneous ODE:

$$
\begin{aligned}
0= & -\beta^{\psi} H^{-1}+\psi \beta+\frac{(1-\psi)(\mu-r)^{2}}{2 \gamma} y_{t}-\frac{\rho \sigma(\mu-r)(1-\gamma)}{\gamma} \frac{H_{y}}{H} y_{t} \\
& +r(1-\psi)+\frac{\rho^{2} \sigma^{2}(1-\gamma)^{2}}{2 \gamma(1-\psi)}\left(\frac{H_{y}}{H}\right)^{2} y_{t}-\frac{H_{y}}{H} \kappa\left(\theta-y_{t}\right)
\end{aligned}
$$




$$
+\frac{\sigma^{2}}{2}\left(\frac{1-\gamma}{1-\psi}+1\right)\left(\frac{H_{y}}{H}\right)^{2} y_{t}-\frac{\sigma^{2}}{2} \frac{H_{y y}}{H} y_{t}
$$

Unfortunately, equation (19) is a non-linear ODE in $H$ whose analytical solution is unknown except in three special cases: $\log$ utility $(\gamma=\psi \equiv 1)$, constant investment opportunities $(\kappa, \sigma=0)$ and isoelastic utility $(\psi=1 / \gamma)$ plus perfect instantaneous correlation between the state variable and returns $(|\rho|=1)$. The first two cases are well-known from Merton's $(1969,1971,1973)$ work. The third case has been explored by Wachter (1998) in a model whose state variable is the expected excess return. We show here that a similar result holds when the state variable is volatility. ${ }^{9}$ In fact, it is easy to show that Wachter's point is general: A closed form solution exists whenever utility is isoelastic and there is perfect positive or negative correlation between the state variable and asset returns. In this case, the resulting equation is a non-homogeneous version of the Gauss' hypergeometric ODE. Therefore, equation (19), specialized for $|\rho|=1$, results in a closed-form solution in terms of the confluent hypergeometric function. This solution is given in Polyanin and Zaitsev (1995, p.143). ${ }^{10}$

However, assuming perfect correlation between changes in volatility and asset returns is not empirically plausible. In that case, (19) has no exact closed-form solution, even if $\psi=1 / \gamma$. Nevertheless, it is still possible to find approximate analytic solu-

\footnotetext{
${ }^{9}$ In concurrent work with this paper, Liu (1998) also shows a similar result.

${ }^{10}$ The solution to this equation is available from the authors. It is a linear combination of confluent hypergeometric functions. However, the rather abstruse form of these functions makes it dificult to obtain any economic insights from the solution. The reader should also refer to Wachter (1998). Using the Cox-Huang approach, she is able to write the optimal policies as integrals of linear and quadratic functions of the state variable. This allows her to obtain more insights about the economic significance of the solution.
} 
tions that gives us a deeper understanding of the problem. We present two approaches for finding analytic solutions. The first approach is based on a log-linear expansion of the consumption-wealth ratio around its unconditional mean. This is exactly the same type of approximation that Campbell (1993) and Campbell and Viceira (1998, 1999) pursue in discrete time. However, while they use the approximation to linearize the log budget constraint, we use it to linearize the Bellman equation. The second approach is to approximate the solution to the nonlinear ODE (18) around the exact solution that obtains when $\psi=1 .^{11}$

We can view these two approaches as particular classes of the perturbation methods of approximation described in Judd (1998). The nature of the approximation is very different in each case. The first approximate solution method finds a solution around a particular point in the state space - the unconditional mean of the log consumption-wealth ratio. This solution will be close to the exact solution provided that the consumption-wealth ratio is not too variable. The second method finds a solution around a particular point in the preference space $-\psi=1$. This solution will be accurate when the elasticity of intertemporal substitution is close to one, but it is unlikely to be accurate for values of $\psi$ far from one. By contrast, the first method is also accurate for values of $\psi$ close to one - because the consumption-wealth ratio is constant when $\psi=1-$, but it can also be accurate for values of $\psi$ far from $1 .{ }^{12}$

We are interested in exploring the optimal consumption and portfolio policies of

\footnotetext{
${ }^{11}$ Note that this second approach includes, as a special case, a third approach consisting in approximating the solution to (18) around the exact known solution for a log-utility investor $(\gamma=\psi \equiv 1)$.

${ }^{12}$ In a model with time-varying expected returns, Campbell, Cocco, Gomes, Maenhout and Viceira (1998) show that this approximation method is a good approximation to the true solution for values of $\psi$ far from one.
} 
investors with low elasticity of intertemporal substitution for two reasons. First, the empirical estimates of $\psi$ available from aggregate data are very close to zero (Hall 1988, Campbell and Mankiw 1989, Campbell 1999). Second, we want to explore the solution when investors have time-additive, isoelastic power utility - in which case $\psi=1 / \gamma$-for a wide range of values of the coefficient of relative risk aversion. Accordingly we choose to present the first solution approach in the main text of the paper, and we show the second approach in appendix A.

As mentioned above, the solution approach we use in the main text of the paper is based on a log-linear expansion of the consumption-wealth ratio around its unconditional mean. To see how this works, note that the envelope condition (9) implies

$$
\beta^{\psi} H^{-1}=\exp \left\{c_{t}-x_{t}\right\}
$$

where $c_{t}-x_{t}=\log \left(C_{t} / X_{t}\right)$. Therefore, using a first-order Taylor expansion of $\exp \left\{c_{t}-\right.$ $\left.x_{t}\right\}$ around $\mathrm{E}\left[c_{t}-w_{t}\right] \equiv(\overline{c-x})$ we can write

$$
\beta^{\psi} H^{-1} \approx h_{0}+h_{1}\left(c_{t}-x_{t}\right)
$$

where $h_{0}=\exp \{\overline{c-x}\}[1-(\overline{c-x})]$ and $h_{1}=\exp \{\overline{c-x}\}$.

Substituting (20) for $\beta^{\psi} H^{-1}$ in the first term of (19), it is easy to see that the resulting ODE has a solution of the form $H=\exp \left\{A y_{t}+B\right\}$. Note that this solution implies $c_{t}-x_{t}=-A y_{t}-B+\psi \log \beta$, i.e., the $\log$ consumption-wealth ratio is linear in precision.

Our approach replaces the term that causes the non-linear ODE (19) to be nonsolvable analytically with a log-linear approximation that transforms the equation into another ODE with a known analytic solution. If the log-linear approximation 
is accurate, the exact analytic solution to the approximate ODE will also verify the original ODE subject to some approximation error. In this sense it is an approximate analytic solution. We show below that the approximation error is zero for the special cases of $\log$ utility and constant investment opportunities.

The approximate ODE leads to two algebraic equations for $A$ and $B$ similar to the equations found in the $\psi=1$ case:

$$
\begin{aligned}
a A^{2}+b A+c & =0, \\
h_{0}-h_{1} B-\psi \beta-r(1-\psi)+\kappa \theta A & =0,
\end{aligned}
$$

where

$$
\begin{aligned}
a & =\frac{\sigma^{2}}{2 \gamma}\left(\frac{1-\gamma}{1-\psi}\right)\left[\gamma\left(1-\rho^{2}\right)+\rho^{2}\right], \\
b & =\left(h_{1}+\kappa\right)-\frac{(1-\gamma) \rho \sigma(\mu-r)}{\gamma}, \\
c & =\frac{(1-\psi)(\mu-r)^{2}}{2 \gamma} .
\end{aligned}
$$

Using the same reasoning as in the $\psi=1$ case, we choose $A$ to be the root associated with the positive root of the discriminant in (21).

The following proposition gives the approximate value function for the problem:

Proposition 3 The indirect utility function, $J\left(X_{t}, y_{t}\right) \equiv J\left(X_{t}, 1 / v_{t}\right)$ is given by

$$
J\left(X_{t}, \frac{1}{v_{t}}\right)=\exp \left\{-\left(\frac{1-\gamma}{1-\psi}\right)\left(\frac{A}{v_{t}}+B\right)\right\} \frac{X_{t}^{1-\gamma}}{1-\gamma},
$$

where $A$ is the solution associated to the positive root of the discriminant of the quadratic equation (21), and $B$ is the solution to the linear equation (22). $A /(1-\psi)$ 
does not depend on $\psi$ except through the loglinearization constant $h_{1}$. Moreover, $\gamma>1$ implies $A /(1-\psi)<0$.

Proof. The proof for this proposition follows immediately from (19), (20) and (21)-(22), using $y_{t}=1 / v_{t}$.

Substituting the solution for the indirect utility function given in Proposition 3 into (9) and (10), we can solve for the optimal policies:

Proposition 4 The optimal consumption and portfolio rules implied by Proposition 1 are

$$
\frac{C_{t}}{X_{t}}=\beta^{\psi} \exp \left\{-\frac{A}{v_{t}}-B\right\}
$$

and

$$
\pi_{t}=\frac{\mu-r}{\gamma v_{t}}-\frac{(1-\gamma) \rho \sigma}{\gamma} \cdot \frac{A}{1-\psi} \cdot \frac{1}{v_{t}} .
$$

Proof. The proof for this proposition follows immediately from Proposition 3 and (9)-(10), using $y_{t}=1 / v_{t}$.

Proposition 4 shows that the optimal log consumption-wealth ratio is a linear function of the instantaneous precision of the risky asset's returns. Moreover, Proposition 3 implies that $A /(1-\psi)<0$ when $\gamma>1 .{ }^{13}$ Therefore, the consumption-wealth ratio is a decreasing monotonic function of volatility for investors with $\gamma>1$ and $\psi<1$, while it is an increasing function of volatility for investors with $\gamma>1$ and $\psi>1$. This reflects the intertemporal income and substitution effects of volatility on

\footnotetext{
${ }^{13}$ When $\gamma<1$, it is difficult to $\operatorname{sign} A$.
} 
consumption. For investor whose elasticity of intertemporal substitution of consumption $(\psi)$ is smaller than one, the income effect of an unexpected change in return volatility is always larger than the intertemporal substitution effect. For example, a sudden increase in volatility implies a deterioration in investment opportunities, because there is more uncertainty about future returns which is not compensated by an increase in expected returns. This creates a positive intertemporal substitution effect on consumption - because the investment opportunities available are not as good as they are at other times - but also a negative income effect - because increased uncertainty increases the marginal utility of consumption. For investors with $\psi<1$, the income effect dominates the substitution effect and they reduce their current consumption relative to wealth. For investors with $\psi>1$, the substitution effect dominates, and they increase their current consumption relative to wealth.

The properties of the optimal portfolio demand are similar to the properties in the $\psi=1$ case, which we have already discussed in depth in section 3 . We only need to add that Proposition 3 implies that the optimal portfolio demand for the risky asset given in (4) does not depend on $\psi$, except through the loglinearization parameter $h_{1}$. The calibration exercise presented in section 7 shows that this effect is quantitatively negligible. Campbell and Viceira $(1998,1999)$ note a similar result when expected returns and interest rates are time-varying.

An important feature of this approximate solution is that it delivers the exact solution in those cases where this solution is known. When $\gamma=\psi \equiv 1$, by direct substitution into Propositions 3 and 4 we find that $A=0$, so that $C_{t} / X_{t}=\beta$ and $\pi_{t}=(\mu-r) / v_{t}$. This is the exact solution to the problem with log utility reported in Merton (1969). 
When $\psi=1$ but $\gamma \neq 1, A=0$ and $C_{t} / X_{t}=\beta$. However $A /(1-\psi) \neq 0$ and the hedging component of $\pi_{t}$ does not vanish. That is, the optimal consumption rule is myopic, while the optimal portfolio rule is not. This is the case discussed in section 3 . When $\gamma=1$ but $\psi \neq 1$, the result is reversed: The hedging component of $\pi_{t}$ vanishes and $\pi_{t}=(\mu-r) / v_{t}$, but consumption relative to wealth is still a function of $1 / v_{t}$.

Finally, when investment opportunities are constant (implying $\kappa, \sigma=0$ and $v_{t} \equiv$ $v$ ), both policies are myopic. Substituting into (21) and (22), we obtain

$$
\frac{C_{t}}{X_{t}}=\psi \beta+\frac{1}{2}(1-\psi) \frac{(\mu-r)^{2}}{\gamma v}+(1-\psi) r,
$$

and $\pi_{t}=(\mu-r) / \gamma v$. This is a generalized version of the exact solution given in Merton (1969) for the power utility case $(\psi=1 / \gamma)$.

\section{Consumption and Portfolio Choice When Ex- pected Excess Returns Covary with Volatility}

The previous analysis of optimal consumption and portfolio choice with stochastic volatility is based on the assumption that expected returns are constant. A natural extension of this analysis is to allow for expected excess returns to change linearly with volatility:

$$
\mathrm{E}_{t}\left[\frac{d S_{t}}{S_{t}}-r d t\right]=\alpha_{0}+\alpha_{1} v_{t}
$$

Guessing the same functional forms for $J\left(X_{t}, y_{t}\right)$ and $I\left(y_{t}\right)$ as in section 4 , it is straightforward to show that the Bellman equation simplifies to an ODE in $H\left(y_{t}\right)$ for which there is a closed form solution, provided that we make the approximation 
$\beta^{\psi} H^{-1} \approx h_{0}+h_{1}\left(c_{t}-x_{t}\right)$. (Details are given in Appendix A). The solution takes the form

$$
H=\exp \left\{A_{1} \log y_{t}+A_{2} y_{t}+B\right\}
$$

where $A_{1}$ and $A_{2}$ solve two independent quadratic equations and $B$ solves an equation which is linear, given $A_{1}$ and $A_{2} \cdot{ }^{14}$

The approximation implies the following optimal policies:

Proposition 5 The optimal consumption and portfolio rules when $\mathrm{E}_{t}\left[\left(d S_{t} / S_{t}\right)-\right.$ $r d t]=\alpha_{0}+\alpha_{1} v_{t}$ are

$$
\frac{C_{t}}{X_{t}}=\beta^{\psi} \exp \left\{A_{1} \log v_{t}-\frac{A_{2}}{v_{t}}-B\right\}
$$

and

$$
\pi_{t}=\frac{1}{\gamma}\left(\alpha_{1}+\alpha_{0} \frac{1}{v_{t}}\right)-\frac{(1-\gamma) \rho \sigma}{\gamma} \cdot\left(\frac{A_{1}}{1-\psi}+\frac{A_{2}}{1-\psi} \frac{1}{v_{t}}\right),
$$

where both $A_{1} /(1-\psi)$ and $A_{2} /(1-\psi)$ do not depend on $\psi$ except through the loglinearization constant $h_{1}$. Moreover, $\gamma>1$ implies $A_{1} /(1-\psi)>0$ and $A_{2} /(1-\psi)<0$.

Proof. See appendix A. Note that $y_{t}=1 / v_{t}$.

Proposition 5 shows that both the myopic component and the hedging component of portfolio demand are affine functions of precision. Since $A_{1} /(1-\psi)>0$, the sign of the intercept of the hedging component is positive when $\gamma>1$ and $\rho>0$. In this case negative covariation between excess returns and volatility creates an extra positive hedging demand which is independent of the level of volatility. This positive hedging

\footnotetext{
${ }^{14}$ When we substitute $h_{0}+h_{1}\left(c_{t}-x_{t}\right)$ for $\beta^{\psi} H_{t}^{-1}$ in the Bellman equation, we still need to do a further approximation of $-\log y_{t}=\log v_{t}$ around its conditional mean.
} 
component offsets (totally or partially) the negative hedging demand coming from pure changes in volatility. Appendix A shows that the magnitude of this component depends on the magnitude of $\alpha_{1}$, the slope of the expected return function, but its sign is independent of the sign of $\alpha_{1} \cdot{ }^{15}$

The special case $\alpha_{0}=0$ is particularly useful to understand why the intercept of the hedging component is always positive when $\gamma>1$ and $\rho>0$ regardless of the sign of $\alpha_{1}$, because in this case hedging demand is determined solely by the constant intercept term. (Appendix A shows that, when $\alpha_{0}=0$, we have that $A_{2}=0$, while $A_{1}$ is not necessarily zero). Moreover, $\alpha_{0}=0$ implies that the myopic component of portfolio demand is also constant, so that the optimal total portfolio demand for the risky asset reduces to the following state-independent rule:

$$
\pi_{t} \equiv \pi=\frac{\alpha_{1}}{\gamma}-\frac{(1-\gamma) \rho \sigma}{\gamma} \cdot \frac{A_{1}}{1-\psi} .
$$

The intuition behind this result is the following. Suppose for simplicity that $r_{f}=0$, so that the expected return on wealth is $\pi \alpha_{1} v_{t}$, and the Sharpe ratio for the risky asset is $\alpha_{1} \sqrt{v_{t}}$. If $\alpha_{1}>0$, the investor can only have a positive expected return on wealth by holding a long position on the risky asset. When $\pi>0$, the expected return on wealth is increasing in volatility. An increase in volatility represents an improvement in investment opportunities, because it increases the Sharpe ratio for the risky asset. In this case, a negative correlation between unexpected excess returns and shocks to volatility $(\rho>0)$ makes the risky asset a good instrument to hedge consumption against a deterioration in investment opportunities, because low expected returns on wealth - declines in volatility - tend to coincide with positive

\footnotetext{
${ }^{15}$ Appendix A shows that $A_{1}$ depends on $\alpha_{1}$ but not on $\alpha_{0}$ (except through $h_{1}$ ), while $A_{2}$ depends on $\alpha_{0}$ but not on $\alpha_{1}$ (again, except through $h_{1}$ ).
} 
unexpected returns on the risky asset that in turn deliver positive realized returns on wealth - because $\pi>0$. Therefore, investors with $\gamma>1$ will optimally have a positive hedging demand for the risky asset.

If $\alpha_{1}<0$, the investor must hold a short position on the risky asset to have a positive expected return on wealth. When $\pi<0$, the expected return on wealth is still increasing in volatility. An increase in volatility still means an improvement in investment opportunities, because investors who hold short positions on an asset benefit from changes in investment opportunities that make the Sharpe ratio for this asset more negative. A negative correlation between unexpected excess returns and shocks to volatility $(\rho>0)$ implies that low expected returns on wealth - declines in volatility - tend to coincide with positive returns on the risky asset that now deliver negative realized returns on wealth-because $\pi<0$. Therefore, even though shorting the risky asset is the only way to make positive returns on wealth on average, risk averse investors will want to temper this short position with a positive hedging demand to avoid having too large negative returns on wealth when investment opportunities are poor. This explains why hedging demand is always positive regardless of the sign of $\alpha_{1}$ when $\gamma>1$ and $\rho>0$.

\section{Model Estimation: Spectral GMM}

A practical implementation of the solution to the dynamic optimization problem (4)-(7) requires an estimation of the parameters of the process (1)-(2). Estimating stochastic volatility models is typically a difficult task. The main difficulty is that volatility is not observable and therefore needs to be integrated out of the condi- 
tional density function. Common techniques used have included simulated method of moments, Kalman filtering, simulated maximum likelihood, and Bayesian estimation. ${ }^{16}$ The choice between these usually becomes a tradeoff between accuracy and computation time.

Chacko and Viceira (1998) and Singleton (1997) have developed an alternative estimation procedure that does not require knowledge of the likelihood function. As an additional benefit, this methodology does not require the discretization of the stochastic process either. It only requires knowledge of its conditional characteristic function. Once this function is known, we can integrate volatility out and obtain the characteristic function of next period's stock price conditional only on the prior period's stock price. Chacko and Viceira (1998) show that we can use generalized method of moments (GMM) to estimate the parameters of the model directly off this conditional characteristic function. Accordingly they call this estimation method Spectral GMM.

The conditional characteristic function of the log stock price is defined as

$$
\phi\left(\log S_{t}, \tau ; \boldsymbol{\theta}, \omega\right)=\mathrm{E}\left[\exp \left\{i \omega \log S_{t+\tau}\right\} \mid \log S_{t}\right],
$$

where $\omega \in \mathbb{R}, \tau \geq 1$, and $\boldsymbol{\theta}=(\mu, \kappa, \theta, \sigma, \rho)^{\prime}$. Note that we are conditioning only on past prices after integrating out volatility. Appendix B derives $\phi\left(\log S_{t}, \tau ; \boldsymbol{\theta}, \omega\right)$ and gives an analytic expression for this function in equation (40).

The characteristic function defines a set of moments of the complex stochastic

\footnotetext{
${ }^{16}$ See Melino and Turnbull (1990), Gallant, Hsieh, and Tauchen (1994), Harvey, Ruiz, and Shephard (1994), Danielsson (1994), and Jacquier, Polson, and Rossi (1994) for examples of these estimation methods in the context of stochastic volatility models.
} 
variable $\exp \left(i \log S_{t+\tau}\right)$. For example, when $\omega=1$, the characteristic function is simply the first non-central moment of $\exp \left(i \log S_{t+\tau}\right)$. For $\omega=2$, the characteristic function is simply the second non-central moment of $\exp \left(i \log S_{t+\tau}\right)$. This procedure can be repeated to obtain any desired number of moments. Furthermore, obtaining these population moments is trivial since it involves only the evaluation of the characteristic function (40).

Equation (28) implicitly defines a set of moment conditions, since

$$
\mathrm{E}\left[\mathbf{h}(\mathbf{X}, t) \otimes\left(\phi\left(\log S_{t}, \tau ; \boldsymbol{\theta}, \omega\right)-\exp \left\{i \omega \log S_{t+\tau}\right\}\right)\right]=0,
$$

for all $\omega \in \mathbb{R} . \mathbf{h}(\mathbf{X}, t)$ is any vector of (real-valued or complex-valued) instruments. Since there are five parameters to be estimated, we choose $\omega=1, \ldots, 5$. We also set $\mathbf{h}(\mathbf{X}, t)=1$ and $\tau=1$ for simplicity.

If we let $g(\boldsymbol{\theta})$ represent the sample analog of the moment conditions in (29), we choose parameter estimates such that

$$
\widehat{\boldsymbol{\theta}}=\arg \min _{\{\boldsymbol{\theta}\}} g(\boldsymbol{\theta})^{\prime} W(\boldsymbol{\theta}) g(\boldsymbol{\theta})
$$

where $W(\boldsymbol{\theta})$ is a positive-definite, symmetric weighting matrix. Because the moment conditions exactly match the number of parameters we have in the model, the parameters are exactly identified, and $g(\boldsymbol{\theta})^{\prime} W(\boldsymbol{\theta}) g(\boldsymbol{\theta})$ attains zero for all choices $W(\boldsymbol{\theta})$. Consequently, we use the identity matrix for $W(\boldsymbol{\theta})$. 


\section{Optimal Consumption and Portfolio Choice with Stochastic Volatility: The U.S. Experience}

This section examines the implications of the patterns in volatility observed in the U.S. stock market for portfolio choice. In order to accomplish this, we first need to estimate the parameters in equations (1) and (2) for the U.S. market. To this end, we use the results in Section 6 to estimate the stochastic volatility model of (1) and (2) using monthly equity returns from January 1926 through December 1997, and annual equity returns from 1871 through 1997. For the monthly estimates we use excess returns (inclusive of dividends) on the CRSP value-weighted portfolio comprising the NYSE, AMEX, and Nasdaq stocks. We compute excess stock returns over the onemonth T-bill yield from the CRSP Risk Free Rates file. For the annual estimates we use excess returns (inclusive of dividends) on the Standard and Poor Composite Stock Price Index over the prime commercial paper rate. These data come from an updated version of the annual long-term stock market dataset in Shiller (1989). ${ }^{17}$ For our calibration exercise we set the riskless rate at $1.5 \%$ per year.

Table 1 reports Spectral GMM parameter estimates and their standard errors. Standard errors are bootstrapped, and parameter estimates are annualized to facilitate their interpretation. The estimates of both the unconditional mean of excess returns and precision have low standard errors in both samples. However, the estimates of the rest of the parameters - particularly the reversion parameter - are less precise.

\footnotetext{
${ }^{17}$ This update is publicly available at Robert Shiller's web home page at [http://www.econ.yale.edu/ ${ }^{\sim}$ shiller/].
} 
These estimates imply a mean excess return around $8 \%$ per year in both samples. The square root of the unconditional mean of the variance process is estimated at around $20 \%$ per year in the monthly sample. This estimate is somewhat larger in the annual sample. ${ }^{18}$ The instantaneous correlation between shocks to volatility and stock returns $(-\rho)$ is negative and relatively large -almost $-54 \%$ in the monthly sample and $-37 \%$ in the annual sample.

The estimate of the reversion parameter $\kappa$ in the precision equation implies a half-life of a shock to precision of about 2 years in the monthly sample. The rate of mean reversion is slower in the annual sample, where the estimate of the half-life of a shock to precision is slightly longer than 16 years. French, Schwert and Stambaugh (1987) and Campbell and Hentschel (1990) have also found a relatively slow speed of adjustment of shocks to stock volatility in low frequency data. This slow reversion to the mean in low frequency data contrasts with the fast speed of adjustment detected in high frequency data by Andersen, Benzoni and Lund (1998). An estimation of the model in this paper using weekly data also shows a quick reversion to the mean. ${ }^{19}$ These results suggest the presence of high frequency and low frequency (or longmemory) components in stock market volatility. Chacko and Viceira (1998) show that a model of multiple additive components in stock return volatility, each one operating at a different frequency, generates a similar pattern in the estimates of $\kappa$ when stock returns are sampled at different frequencies. The high frequency component is unlikely

\footnotetext{
${ }^{18}$ The unconditional mean of the precision process $y$ is $\theta$. A second-order Taylor expansion of $v=1 / y$ around $\theta$ implies an unconditional mean of $v$ equal to $1 / \theta+\sigma^{2} / 2 \theta^{2} \kappa$. The second term comes from the second-order term of the expansion, that involves the unconditional variance of the precision process.

${ }^{19}$ We estimate the half-life of a shock to precision to be about 3 months. We do not report the weekly estimates to save space. However, they are readily available upon request.
} 
to have a large effect on portfolio choice because shocks to volatility have very low persistence. ${ }^{20}$ Accordingly we do not pursue this issue further and we only consider the estimates from the monthly and annual datasets for our calibration exercise.

Tables II explores the implications for portfolio choice of the monthly estimates, while Table III explores the implications of the annual estimates. Panel A of each table reports the mean optimal percentage allocation to stocks for investors with coefficients of relative risk aversion $(\gamma)$ equal to $\{1,1.5,2,4,10,20,40\}$, elasticities of intertemporal substitution $(\psi)$ equal to $\{1,1 / 1.5,1 / 2,1 / 4,1 / 10,1 / 20,1 / 40\}$ and rate of time preference $(\beta)$ equal to $6 \%$ annually. ${ }^{21}$ We have shown that portfolio choice does not depend on the investor's elasticity of intertemporal substitution except through the loglinearization parameter $h_{1}$. Panel A of each table shows that the indirect effect of $\psi$ on $\pi_{t}$ is negligible. Campbell and Viceira (1999) have found a similar result when expected returns are time-varying. By contrast, the total optimal portfolio allocation to stocks is inversely related to the coefficient of relative risk aversion.

Panel B evaluates the empirical importance of hedging demands. It reports the percentage ratio of hedging portfolio demand over myopic portfolio demand which, as shown in Propositions 2 and 4, is independent of the level of volatility. Since our estimate of the correlation between shocks to volatility and unexpected stock returns is negative in both samples, hedging demand is negative for all $\gamma>1$. Hence this

\footnotetext{
${ }^{20}$ We have shown in Section 4 that optimal portfolio demand is increasing in the persistence of shocks to volatility.

${ }^{21}$ Note that Proposition 2 implies that the optimal percentage allocation to stocks is linear in the inverse of the stock return volatility. Hence, the mean allocation to stocks differs from the allocation at the mean of the volatility process by a Jensen's Inequality term.
} 
ratio tells us the reduction in myopic portfolio demand due to hedging considerations. Panel B of Table II shows that our estimates of the volatility process for monthly US stock returns imply a small impact of time-variation in volatility on the optimal portfolio demand for stocks. Even for highly risk averse investors $(\gamma=40)$, hedging demand reduces myopic demand by less than $4 \%$. By contrast, the estimates of the volatility process based on the annual sample imply a much larger impact of volatility on optimal portfolio demand. Hedging demand reduces myopic demand by at least $4 \%$ for investors with $\gamma=4$. For highly risk averse investors $(\gamma=40)$, it can reduce myopic demand by almost $16 \%$.

Figures 1 and 2 are helpful to understand these results. Propositions 2 and 4 show that hedging demand depends on the instantaneous correlation between shocks to volatility and stock returns $(-\rho)$ and the persistence of these shocks $(\kappa)$. Figure 1 plots the ratio of hedging demand to myopic demand for values of $\kappa$ implying a half-life of a shock between 6 months and 30 years - and holding the rest of the parameters at the values implied by the monthly dataset. Figure 2 repeats the experiment, though this time the parameter that varies is the correlation coefficient. The vertical line in each plot intersects the horizontal axis at the parameter value implied by the monthly dataset.

Figures 1 and 2 suggest that hedging demand is more sensitive to the persistence in shocks to volatility than to the correlation between these shocks and stock returns. Figure 1 shows that increasing persistence has noticeable effects on hedging demand, even for investors with low coefficients of relative risk aversion. For example, an investor with $\gamma=4$ would reduce her myopic demand by approximately $10 \%$ instead of $2.5 \%$ if the half-life of a shock were 10 years instead of 2 years. By contrast, the 
effect of changing the correlation is much smaller. Even if the correlation between unexpected returns and shocks to volatility were -1 , hedging demand would not reduce myopic demand by more than $6 \%$ for an investor with $\gamma=20$.

Table IV describes the implications for consumption and savings of the estimated volatility process for the monthly sample. Panel A in the table reports the exponentiated optimal mean log consumption-wealth ratio and Panel B reports the long-term expected return on wealth. Panel A shows that optimal consumption depends on both $\gamma$ and $\psi$. It is a positive monotonic function of $\psi$ when $\gamma>1$, while it is a negative monotonic function of $\psi$ when $\gamma=1$. It is independent of $\gamma$ and equal to the rate of time preference $\beta(6 \%)$ when $\psi=1$ - as shown in Section 3.

In the context of a model with time-varying expected returns, Campbell and Viceira (1999) explain the complex patterns we observe in Panel A. Investors in the bottom of the panel are highly risk averse, so they are almost fully invested in stocks; if they are also very reluctant to substitute consumption intertemporally ( $\psi$ close to zero), they optimally choose to consume the long-term yield on wealth - allowing for some precautionary savings. Panel B shows that the optimal consumption-wealth ratio of an investor with $\gamma=40$ and $\psi=1 / 40$ is remarkably close to the long-term expected return on her wealth portfolio. For investors with $\psi$ still close to zero but less risk averse, it is optimal to invest a larger fraction of their wealth in stocks; hence they choose a larger consumption-wealth ratio - though precautionary savings also increase, as they take on more risk. This explains the pattern we observe as we move upwards in Panel A from the south-east corner. When the expected return on wealth is smaller than the rate of time preference, investors who are willing to substitute consumption intertemporally value current consumption more than future 
consumption; hence the increasing pattern in consumption-wealth ratios we observe as we move to the left in Panel A. As we move upwards in the panel this pattern becomes less pronounced - or even reverses - because the long-term expected return on wealth increases and eventually is larger than the rate of time preference.

Table V reports the percentage, annualized volatility of the log consumptionwealth ratio for the monthly sample. Proposition 4 shows that any investor with elasticity of intertemporal substitution different from one is willing to accept volatility (time-variation) in her consumption-wealth ratio. From equation (2) and Proposition 4 , the instantaneous volatility of the log consumption-wealth ratio is equal to $-A \sigma \sqrt{y_{t}}$. Table VI reports this volatility when $y_{t}$ is at its long-term mean $\theta$. This table shows that highly risk-averse investors with low elasticity of intertemporal substitution choose the most volatile consumption-wealth ratios. But even for these investors, the log consumption-wealth ratio exhibits low volatility, both in absolute terms and relative to its mean. For example, for $\psi=1 / 40$, volatility ranges from $2.4 \%$ when $\gamma=1$ to $.07 \%$ when $\gamma=40$. This volatility implies a mean-volatility ratio around 4 when $\gamma=1$ and around 26 when $\gamma=40 .{ }^{22}$

Finally, Table V investigates the effect of covariation between expected returns and volatility on optimal portfolio choice. We assume that expected excess returns are linear in the instantaneous variance of stock returns as in equation (26) of section 5. An estimation of this model using the monthly data set shows that $\alpha_{1}$ is not statistically significant - the point estimate is .75 with a standard error of .41 . Hence we choose to compute optimal allocations for a set of values of $\alpha_{1}$ around zero, holding

\footnotetext{
${ }^{22}$ Incidentally, this result suggests that the approximate analytical solution is likely to be accurate for values of $\psi$ close to zero.
} 
the rest of the parameters at the values implied by the monthly dataset. Each row of the table reports allocations corresponding to this set of values of $\alpha_{1}$ given a particular value of $\gamma$. All entries in the table assume $\psi=1 / 2$. Proposition 5 shows that both components of optimal portfolio demand (myopic and hedging) are affine functions of the reciprocal of instantaneous volatility. Panel A reports the mean optimal allocation to stocks, while Panel B reports the percentage value of the intercept of the hedging demand and Panel $\mathrm{C}$ reports the percentage value of the slope of the hedging demand times $\theta$ (the unconditional mean of $y_{t} \equiv 1 / v_{t}$ ).

Panel A shows that $\pi_{t}$ is increasing in $\alpha_{1}$. Panels $\mathrm{B}$ and $\mathrm{C}$ show that this effect operates mainly through the increase in myopic demand caused by an increase in $\alpha_{1}$. As shown in section 5, the intercept of the hedging demand is always positive for $\rho>0$ and $\gamma>1$, while the slope is always negative. The slope of the intertemporal hedging demand captures hedging effects due to uncompensated changes in volatility, while the intercept captures hedging effects of compensated changes in volatility - it is zero when expected excess returns are constant, and it increases as $\alpha_{1}$ becomes larger in absolute value. Table I shows that the effect of the slope is relatively more important than the effect of the intercept, at least for values of $\alpha_{1}$ close to zero. However, both terms are too small in absolute value to have any significant impact on total portfolio demand when using parameter estimates based on the monthly dataset.

\section{Conclusion}

Time-varying conditional volatility is a pervasive characteristic of asset returns. This paper explores the implications of this phenomenon for optimal portfolio choice of 
long-horizon investors using an intertemporal model where consumption is also endogenously determined. We use the Duffie-Epstein (1992) formulation of recursive utility in continuous-time to model investors' preferences. Recursive utility disentangles investors' attitudes towards the intertemporal substitution of consumption from their willingness to take on financial risk, which in the standard power utility model are represented by the same parameter.

We show that optimal portfolio demand for stocks is proportional to precision, the inverse of stock volatility, provided that expected excess returns are constant and all time-variation in the asset's Sharpe ratio is in the denominator. Portfolio demand depends on the investor's coefficient of relative risk aversion, but not on her elasticity of intertemporal substitution; by contrast, optimal consumption relative to wealth depends on both preference parameters. We also show that stochastic volatility produces an optimal intertemporal hedging demand for stocks. This hedging component of portfolio demand is negative when changes in volatility are instantaneously negatively correlated with excess stock returns for those investors whose coefficient of relative risk aversion is larger than one. The absolute size of this demand increases with the size of this correlation, and also with the persistence of shocks to volatility. The ratio of hedging demand to total portfolio demand is constant.

If excess returns covary linearly with volatility, optimal portfolio demand and its hedging component are both affine functions of precision. We show that, when the instantaneous correlation between changes in volatility and excess stock returns is negative and the investor's coefficient of relative risk aversion is larger than one, the intercept of the hedging component is positive, while the slope is negative. The intercept, which is zero when expected returns are constant, captures hedging ef- 
fects of compensated changes in volatility, while the slope captures hedging effects of uncompensated changes in volatility.

Our solution to the intertemporal optimization problem is exact provided that investors' elasticity of intertemporal substitution is one. In all other cases, this solution is approximate, based on a continuous-time loglinear approximation. This approximation is equivalent to the loglinear approach to portfolio choice developed by Campbell and Viceira $(1998,1999)$ for discrete-time models, and it can be viewed as a particular class of the perturbation methods described in Judd (1998).

To evaluate the importance of stochastic volatility for portfolio choice we estimate the process for stochastic volatility using monthly U.S. stock returns from 1926 to 1997 and annual stock returns from 1871 to 1997. To this end we apply the Spectral Generalized Method of Moments of Chacko and Viceira (1998). Spectral GMM provides a flexible instrument to estimate continuous-time models for which ML estimation is not possible because the density function is unknown. This methodology instead utilizes the characteristic function, which is known for a wide array of models.

Our estimates indicate that empirically the instantaneous correlation between changes in volatility and stock returns is large and negative. This negative correlation implies negative hedging portfolio demands for stocks when investors are more risk averse than logarithmic investors. Our estimates also indicate that shocks to volatility are moderately persistent when returns are measured at a monthly frequency, but they much more persistent when returns are measured at an annual frequency. This difference in persistence has important implications for the size of hedging demands. Shocks to volatility must be highly persistent to generate large hedging demands by long-horizon investors. For example, our estimate of the persistence of shocks 
to volatility at a monthly frequency implies only modest hedging demands, even for highly risk averse investors, while the persistence of shocks at an annual frequency implies much larger hedging demands at all levels of risk aversion. In fact, a sensitivity analysis shows that persistence in shocks to volatility is considerably more important than correlation in determining the size of hedging demands.

\section{$9 \quad$ References}

Andersen, Torben, Luca Benzoni and Jesper Lund, 1998, "Estimating Jump-Diffusions for Equity Returns," unpublished paper, Northwestern University.

Ang, Andrew and Geert Bekaert, 1999, "International Asset Allocation with TimeVarying Correlations," NBER Working Paper no. 7056.

Balduzzi, Perluigi and Anthony Lynch, 1997, "Transaction Costs and Predictability: Some Utility Cost Calculations," Journal of Financial Economics 52, 47-78.

Barberis, Nicholas C., 1996, "How Big Are Hedging Demands? Evidence from LongHorizon Asset Allocation," unpublished paper, Harvard University.

Bollerslev, Tim, Ray Y. Chou and Kenneth Kroner, 1992, "ARCH Modeling in Finance," Journal of Econometrics 52, 5-59.

Brennan, Michael J., Eduardo S. Schwartz, and Ronald Lagnado, 1996, "The Use of Treasury Bill Futures in Strategic Asset Allocation Programs", Finance Working Paper 7-96, Anderson Graduate School of Management, UCLA, Los Angeles, CA. 
Brennan, Michael J., Eduardo S. Schwartz, and Ronald Lagnado, 1997, "Strategic Asset Allocation", Journal of Economic Dynamics and Control, 21, 1377-1403.

Campbell, John Y., 1993, "Intertemporal Asset Pricing without Consumption Data", American Economic Review 83, 487-512.

Campbell, John Y., 1999, "Asset Prices, Consumption, and the Business Cycle", forthcoming in John Taylor and Michael Woodford eds. Handbook of Macroeconomics, North-Holland, Amsterdam.

Campbell, John Y., João Cocco, Francisco Gomes, Pascal J. Maenhout, and Luis M. Viceira, "Stock Market Mean Reversion and the Optimal Equity Allocation of a Long-Lived Investor," unpublished paper, Harvard University, 1998.

Campbell, John Y. and Ludger Hentschel, 1992, "No News is Good News. An Asymmetric Model of Changing Volatility in Stock Returns," Journal of Financial Economics 31, 281-318.

Campbell, John Y., Andrew W. Lo and A. Craig MacKinlay, 1997, The Econometrics of Financial Markets, Princeton University Press, Princeton, NJ.

Campbell, John Y., and N. Gregory Mankiw, "Consumption, Income, and Interest Rates: Reinterpreting the Time-Series Evidence," in NBER Macroeconomics Annual 1989 (Cambridge, MA: MIT Press, 1989).

Campbell, John Y. and Luis M. Viceira, 1999, "Consumption and Portfolio Decisions When Expected Returns Are Time Varying", Quarterly Journal of Economics 114, 433-495. 
Campbell, John Y. and Luis M. Viceira, 1998, "Who Should Buy Long-Term Bonds?", NBER Working Paper No. 6801.

Cecchetti, Steven, Pok-sang Lam and Nelson C. Mark, 1990, "Testing Volatility Restrictions on Intertemporal Marginal Rates of Substitution Implied by Euler Equations and Asset Returns", Journal of Finance 49, 123-152.

Chacko, George and Luis M. Viceira, 1998, "Spectral GMM Estimation of ContinuousTime Processes," manuscript, Harvard University.

Cochrane, John and Lars P. Hansen, 1992, "Asset Pricing Explorations for Macroeconomics", in NBER Macroeconomics Annual 1992, Massachusetts Institute of Technology Press, Cambridge, MA, 115-165.

Cox, John C. and Chi-fu Huang, 1989, "Optimal Consumption and Portfolio Policies when Asset Prices Follow a Diffusion Process", Journal of Economic Theory 49, $33-83$.

Danielsson, J. (1994): "Stochastic Volatility in Asset Prices: Estimation with Simulated Maximum Likelihood," Journal of Econometrics, 54.

Engle, Robert F., Takatoshi Ito and Wen-Ling Lin, 1990, "Meteor Showers or Heat Waves? Heteroskedastic Intra-Daily Volatility in the Foreign Exchange Market," Econometrica 58, 525-542.

Epstein, Lawrence and Stanley Zin, 1989, "Substitution, Risk Aversion, and the Temporal Behavior of Consumption and Asset Returns: A Theoretical Framework", Econometrica 57, 937-69. 
Epstein, Lawrence and Stanley Zin, 1991, "Substitution, Risk Aversion, and the Temporal Behavior of Consumption and Asset Returns: An Empirical Investigation", Journal of Political Economy 99, 263-286.

Fisher, Mark and Christian Gilles, 1998, "Consumption and Asset Prices with Recursive Preferences", unpublished paper, Board of Governors of the Federal Reserve System.

French, Kenneth R., G. William Schwert and Robert F. Stambaugh, "Expected Stock Returns and Volatility," Journal of Financial Economics 19, 3-29.

Gallant, A.R., D. Hsieh, and G. Tauchen (1994): "Estimation of Stochastic Volatility Models with Diagnostics," unpublished paper, Duke University.

Giovannini, Alberto and Philippe Weil, 1989, "Risk Aversion and Intertemporal Substitution in the Capital Asset Pricing Model", NBER Working Paper No. 2824 .

Hall, Robert E., "Intertemporal Substitution in Consumption," Journal of Political Economy XCVI (1988), 339-357.

Hansen, Lars P. and Ravi Jagannathan, 1991, "Restrictions on Intertemporal Marginal Rates of Substitution Implied by Asset Returns", Journal of Political Economy 99, 225-262.

Harvey, A., E. Ruiz, and N. Shephard (1994): "Multivariate Stochastic Variance Models," Review of Economic Studies 61, 247-264.

Jacquier, E., N. Polson, and P. Rossi (1994): "Bayesian Analysis of Stochastic Volatility Models," Journal of Business and Economic Statistics 12, 371-389. 
Judd, Kenneth L., 1998, Numerical Methods in Economics, The MIT Press, Cambridge, MA.

Kim, Tong Suk and Edward Omberg, 1996, "Dynamic Nonmyopic Portfolio Behavior", Review of Financial Studies 9, 141-161.

Kocherlakota, Narayana R., 1996, "The Equity Premium: It's Still a Puzzle", Journal of Economic Literature 34, 42-71.

Liu, Jun, 1998, "Portfolio Selection in Stochastic Environments," unpublished paper, Stanford University.

Mehra, Rajnish and Edward C. Prescott, 1985, "The Equity Premium: A Puzzle", Journal of Monetary Economics 15, 145-161.

Melino, A. and S. Turnbull (1990): "Pricing Foreign Currency Options with Stochastic Volatility," Journal of Econometrics 45, 239-265.

Merton, Robert C., 1969, "Lifetime Portfolio Selection Under Uncertainty: The Continuous Time Case", Review of Economics and Statistics 51, 247-257.

Merton, Robert C., 1971, "Optimum Consumption and Portfolio Rules in a ContinuousTime Model", Journal of Economic Theory 3, 373-413.

Merton, Robert C., 1973, "An Intertemporal Capital Asset Pricing Model", Econometrica 41, 867-87.

Merton, Robert C., 1990, Continuous Time Finance, Basil Blackwell, Cambridge, MA. 
Schroder, Mark and Costis Skiadas, 1997, "Optimal Consumption and Portfolio Selection with Stochastic Differential Utility," unpublished paper, Michigan State University and Northwestrn University.

Shiller, Robert J., 1989, Market Volatility, MIT Press, Cambridge, MA.

Singleton, Kenneth J., 1997, "Estimation of Affine Asset Pricing Models Using the Empirical Characteristic Function," unpublished paper, Stanford University.

Viceira, Luis M., 1998, "Optimal Portfolio Choice for Long-Horizon Investors with Nontradable Income", unpublished paper, Harvard University.

Wachter, Jessica, 1998, "Portfolio and Consumption Decisions Under Mean-Reverting Returns: An Exact Solution for Complete Markets," unpublished paper, Harvard University. 


\section{A Appendix A: Alternative Approximate Analyt- ical Solution to the Bellman Equation}

This appendix derives the second perturbation approach to find an approximate analytical solution to the problem. This second approach works by finding a solution to the nonlinear ODE (18) around the exact solution that obtains when $\psi=1$-which is derived in section 3 .

We first restate the Bellman equation obtained in (18) above:

$$
\begin{aligned}
0= & -\frac{1}{1-\psi} \beta^{\psi} I^{1+\frac{1-\psi}{1-\gamma}}+\frac{\psi}{1-\psi} \beta I+\frac{(\mu-r)^{2}}{2 \gamma} I y_{t}+\frac{\rho \sigma(\mu-r)}{\gamma} I_{y} y_{t}+r I \\
& +\frac{\rho^{2} \sigma^{2}}{2 \gamma} \frac{\left(I_{y}\right)^{2}}{I_{t}} y_{t}+\frac{1}{1-\gamma} I_{y} \kappa\left(\theta-y_{t}\right)+\frac{\sigma^{2}}{2(1-\gamma)} I_{y y} y_{t} .
\end{aligned}
$$

We apply the perturbation approach by simply taking a 1st-order expansion of the first term, $I^{1+\frac{1-\psi}{1-\gamma}}$, around the parameter value $\psi=1$. This yields

$$
I^{1+\frac{1-\psi}{1-\gamma}} \approx I+\frac{1-\psi}{1-\gamma} I \log I .
$$

Substituting this into (30) gives

$$
\begin{aligned}
0= & -\frac{\beta^{\psi}}{1-\psi} I-\frac{\beta^{\psi}}{1-\gamma} I \log I+\frac{\psi}{1-\psi} \beta I+\frac{(\mu-r)^{2}}{2 \gamma} I y_{t}+\frac{\rho \sigma(\mu-r)}{\gamma} I_{y} y_{t}+r I \\
& +\frac{\rho^{2} \sigma^{2}}{2 \gamma} \frac{\left(I_{y}\right)^{2}}{I_{t}} y_{t}+\frac{1}{1-\gamma} I_{y} \kappa\left(\theta-y_{t}\right)+\frac{\sigma^{2}}{2(1-\gamma)} I_{y y} y_{t} .
\end{aligned}
$$

We can now solve this equation exactly. The solution is given by

$$
I=\exp \left\{A y_{t}+B\right\}
$$

where $A$ satisfies the following quadratic equation:

$$
a A^{2}+b A+c=0
$$


with

$$
\begin{aligned}
a & =\frac{\sigma^{2}}{2 \gamma(1-\gamma)}\left[\gamma\left(1-\rho^{2}\right)+\rho^{2}\right], \\
b & =\frac{\rho \sigma(\mu-r)}{\gamma}-\frac{\beta^{\psi}+\kappa}{1-\gamma}, \\
c & =\frac{(\mu-r)^{2}}{2 \gamma},
\end{aligned}
$$

and $B$ is given by the following expression:

$$
B=\frac{1-\gamma}{\beta^{\psi}}\left(\frac{\kappa \theta}{1-\gamma} A+\frac{\beta \psi}{1-\psi}-\frac{\beta^{\psi}}{1-\psi}+r\right) .
$$

Note that equations (31)-(33) are identical to equations (15)-(17).

Thus, the value function, $J\left(X_{t}, y_{t}\right) \equiv J\left(X_{t}, 1 / v_{t}\right)$, is given the expression

$$
J\left(X_{t}, \frac{1}{v_{t}}\right)=\exp \left\{\frac{A}{v_{t}}+B\right\} \frac{X_{t}^{1-\gamma}}{1-\gamma}
$$

from which optimal consumption and portfolio choice may be calculated by simply plugging into the first-order conditions (9) and (10).

\section{B Appendix B: Derivation of Optimal Policies Un- der Time-Varying Expected Returns}

The simplified ODE for this problem is given by:

$0=-\beta^{\psi} H^{-1}+\psi \beta+\frac{(1-\psi)}{2 \gamma}\left(2 \alpha_{0} \alpha_{1}+\alpha_{0}^{2} y_{t}+\frac{\alpha_{1}^{2}}{y_{t}}\right)-\frac{\rho \sigma(1-\gamma)}{\gamma}\left(\alpha_{0} y_{t}+\alpha_{1}\right) \frac{H_{y}}{H} y_{t}$ 


$$
\begin{aligned}
& +r(1-\psi)+\frac{\rho^{2} \sigma^{2}(1-\gamma)^{2}}{2 \gamma(1-\psi)}\left(\frac{H_{y}}{H}\right)^{2} y_{t}-\frac{H_{y}}{H} \kappa\left(\theta-y_{t}\right) \\
& +\frac{\sigma^{2}}{2}\left(\frac{1-\gamma}{1-\psi}+1\right)\left(\frac{H_{y}}{H}\right)^{2} y_{t}-\frac{\sigma_{y}^{2}}{2} \frac{H_{y y}}{H_{t}} y_{t} .
\end{aligned}
$$

We now guess that $H=\exp \left\{A_{1} \log y_{t}+A_{2} y_{t}+B\right\}$ and we make the substitution

$$
\beta^{\psi} H^{-1} \approx h_{0}+h_{1}\left(c_{t}-x_{t}\right)
$$

and

$$
\begin{aligned}
-\log y_{t} & =\log v_{t} \\
& \approx \log \theta_{v}+\frac{1}{\theta_{v}}\left(v-\theta_{v}\right) \\
& =\log \kappa-\log \left(\kappa \theta-\sigma^{2}\right)-1+\frac{\kappa \theta-\sigma^{2}}{\kappa} \frac{1}{y_{t}} .
\end{aligned}
$$

After collecting terms in $1 / y_{t}, y_{t}$ and 1 we find:

$$
\begin{aligned}
0= & \frac{(1-\psi) \alpha_{1}^{2}}{2 \gamma}-\left[\theta\left(h_{1}+\kappa\right)-\left(\frac{h_{1}}{\kappa}+\frac{1}{2}\right) \sigma^{2}+\frac{(1-\gamma) \rho \sigma \alpha_{1}}{\gamma}\right] A_{1}+a A_{1}^{2} \\
0= & \frac{(1-\psi) \alpha_{0}^{2}}{2 \gamma}+\left[\left(h_{1}+\kappa\right)-\frac{(1-\gamma) \rho \sigma \alpha_{0}}{\gamma}\right] A_{2}+a A_{2}^{2} \\
0= & -h_{0}-h_{1} \psi \log \beta-h_{1}\left(\log \kappa-\log \left(\kappa \theta-\sigma^{2}\right)-\frac{\kappa}{\kappa \theta-\sigma^{2}}\right) A_{1}+h_{1} B+\psi \beta \\
& +\frac{2(1-\psi) \alpha_{0} \alpha_{1}}{2 \gamma}-\frac{\rho \sigma(1-\gamma)}{\gamma}\left(\alpha_{0} A_{1}+\alpha_{1} A_{2}\right)+r(1-\psi) \\
& +2 a A_{1} A_{2}+\kappa\left(A_{1}-\theta A_{2}\right)
\end{aligned}
$$

where $a$ is given in (23). The optimal policies obtain immediately from substitution of the value function into the first order conditions (9) and (10).

Coefficient $A_{1}$ obtains as the solution to the quadratic equation (35). When $\gamma>1$, this equation has two real roots of opposite sign. However, only the root 
associated with the negative root of the discriminant maximizes the value function and ensures that $A_{1}=0$ when $\alpha_{1}=0$-i.e., it ensures the mutual consistency between the solution given in Proposition 4 and this solution. It is immediate then to show that $A_{1} /(1-\psi)>0$ when $\gamma>1$. Note that $A_{1}$ does not depend on $\alpha_{0}$.

Similarly, $A_{2}$ obtains as the solution to the quadratic equation (36). Simple inspection of this equation and equation (21) shows that they are identical except that $\alpha_{0}$ replaces $(\mu-r)$ in (36). Hence the analysis of $A$ presented in section 4 is also valid for $A_{1}$, so that $A_{1}$ is given by the root associated with the positive root of the discriminant of equation (36). It is immediate then to show that $A_{2} /(1-\psi)<0$ when $\gamma>1$, and $A_{2}=0$ when $\alpha_{0}=0$. Note that $A_{2}$ does not depend on $\alpha_{1}$.

\section{Appendix C: Derivation of the Conditional Char- acteristic Function.}

The conditional characteristic function for the $(\log )$ stock price process is given by the solution to the following Kolmogorov backward equation (KBE):

$$
\begin{aligned}
0= & \frac{1}{2 y_{t}} \frac{\partial^{2} \phi}{\partial\left(\log S_{t}\right)^{2}}+\left(\mu-\frac{1}{2 y_{t}}\right) \frac{\partial \phi}{\partial \log S_{t}}+\kappa\left(\theta-y_{t}\right) \frac{\partial \phi}{\partial y_{t}}+\frac{1}{2} \sigma^{2} y_{t} \frac{\partial^{2} \phi}{\partial y_{t}^{2}} \\
& +\rho \sigma \frac{\partial^{2} \phi}{\partial\left(\log S_{t}\right) \partial y_{t}}-\frac{\partial \phi}{\partial \tau},
\end{aligned}
$$

where $\phi \equiv \phi\left(\log S_{t}, y_{t}, \tau ; \boldsymbol{\theta}, \omega\right)$. The boundary condition for this partial differential equation is simply

$$
\phi\left(\log S_{t+\tau}, y_{t+\tau}, \tau ; \boldsymbol{\theta}, \omega\right)=\exp \left[i \omega \log S_{t+\tau}\right] .
$$


Due to the $1 / 2 y_{t}$ terms in (37), this equation clearly does not fit into the affine specification required in Chacko and Viceira (1998). However, we will use a Taylorseries expansion to linearize this term. We use the approximation

$$
\frac{1}{y_{t}} \approx \frac{2}{\theta}-\frac{1}{\theta^{2}} y_{t} .
$$

With this linearization, the KBE becomes

$$
\begin{aligned}
0= & \frac{1}{2}\left(\frac{2}{\theta}-\frac{1}{\theta^{2}} y_{t}\right) \frac{\partial^{2} \phi}{\partial\left(\log S_{t}\right)^{2}}+\left[\mu-\frac{1}{2}\left(\frac{2}{\theta}-\frac{1}{\theta^{2}} y_{t}\right)\right] \frac{\partial \phi}{\partial \log S_{t}}+\kappa\left(\theta-y_{t}\right) \frac{\partial \phi}{\partial y_{t}} \\
& +\frac{1}{2} \sigma^{2} y_{t} \frac{\partial^{2} \phi}{\partial y_{t}^{2}}+\rho \sigma \frac{\partial^{2} \phi}{\partial\left(\log S_{t}\right) \partial y_{t}}-\frac{\partial \phi}{\partial \tau} .
\end{aligned}
$$

Since the KBE is now a linear equation, we know from Chacko and Viceira (1998) that the characteristic function is exponential affine. The solution to (38) is given by

$$
\phi\left(\log S_{t}, y_{t}, \tau ; \boldsymbol{\theta}, \omega\right)=\exp \left[A(\tau) \log S_{t}+B(\tau) y_{t}+C(\tau)\right],
$$

where

$$
\begin{aligned}
A(\tau) & =i \omega \\
B(\tau) & =\frac{2 r_{1} r_{2}}{\sigma^{2}}\left[\frac{\exp \left(r_{1} \tau\right)-\exp \left(r_{2} \tau\right)}{r_{1} \exp \left(r_{2} \tau\right)-r_{1} \exp \left(r_{1} \tau\right)}\right] \\
C(\tau) & =\left(\mu-\frac{1}{\theta}\right) i \omega \tau+\frac{1}{\theta}(i \omega)^{2} \tau+(\kappa \theta+\rho \sigma i \omega) \frac{2}{\sigma^{2}} \log \left[\frac{r_{2}-r_{1}}{r_{2} \exp \left(r_{1} \tau\right)-r_{1} \exp \left(r_{2} \tau\right)}\right] \\
r_{1} & =-\frac{1}{2} \kappa+\frac{1}{2} \sqrt{\kappa^{2}+\frac{\sigma^{2}}{\theta^{2}} i \omega(i \omega-1)} \\
r_{2} & =-\frac{1}{2} \kappa-\frac{1}{2} \sqrt{\kappa^{2}+\frac{\sigma^{2}}{\theta^{2}} i \omega(i \omega-1)} .
\end{aligned}
$$

Before we proceed to estimate the model, we first need to integrate the unobservable variable $y_{t}$ out of the characteristic function. This is easily accomplished as 
follows. Let $f\left(y_{t}\right)$ denote the unconditional density of volatility. Then,

$$
\begin{aligned}
\int_{0}^{\infty} \phi\left(\log S_{t}, y_{t}, \tau ; \boldsymbol{\theta}, \omega\right) f\left(y_{t}\right) d y_{t} & =\int_{0}^{\infty} \exp \left[A(\tau) \log S_{t}+B(\tau) y_{t}+C(\tau)\right] f\left(y_{t}\right) d y_{t} \\
& =\exp \left[A(\tau) \log S_{t}+C(\tau)\right] \int_{0}^{\infty} \exp \left[B(\tau) y_{t}\right] f\left(y_{t}\right) d y_{t} .
\end{aligned}
$$

Of course, $\int_{0}^{\infty} \exp \left[B(\tau) y_{t}\right] f\left(y_{t}\right) d y_{t}$ is simply the moment-generating function of the square-root process (2). This moment generating function is well known. Therefore, we have the result that the characteristic function of $\log S_{T}$ conditional only on the prior observation of the stock price, $\log S_{t}$, is given by

$$
\phi\left(\log S_{t}, \tau ; \boldsymbol{\theta}, \omega\right)=\exp \left[A(\tau) \log S_{t}+C(\tau)\right]\left[\frac{2 \kappa}{2 \kappa-\sigma^{2} B(\tau)}\right]^{\frac{2 \kappa \theta}{\sigma_{y}^{2}}} .
$$

Thus, we have effectively integrated out the unobservable state variable, $y_{t}$, from the characteristic function and, therefore, from the estimation process. 
TABLE I

Estimates of the Stochastic Process for Returns and Volatility

\begin{tabular}{|c|c|c|}
\hline \multicolumn{3}{|c|}{ Model: } \\
\hline \multicolumn{3}{|c|}{$d S_{t} / S_{t}-d B_{t} / B_{t}=(\mu-r) d t+\sqrt{v_{t}} d W_{s}$} \\
\hline \multicolumn{3}{|c|}{$v_{t}=1 / y_{t}$} \\
\hline \multicolumn{3}{|c|}{$d y_{t}=\kappa\left(\theta-y_{t}\right) d t+\sigma \sqrt{y_{t}} d W_{y}$} \\
\hline \multicolumn{3}{|c|}{$d W_{s} d W_{y}=\rho d t$} \\
\hline \multicolumn{3}{|c|}{ Parameter estimates (s.e.): } \\
\hline & $1926.01-1997.12$ & $1871-1997$ \\
\hline$\mu-r$ & $\begin{array}{c}.0799 \\
(.0238)\end{array}$ & $\begin{array}{c}.0841 \\
(.0370)\end{array}$ \\
\hline$\kappa$ & .3413 & .0426 \\
\hline & $(.3114)$ & $(.0445)$ \\
\hline$\theta$ & 27.7088 & 24.7718 \\
\hline & $(1.8153)$ & $(12.6946)$ \\
\hline$\sigma$ & .6512 & 1.1786 \\
\hline & $(.4855)$ & $(.7065)$ \\
\hline$\rho$ & .5355 & .3708 \\
\hline & $(.2381)$ & $(.3769)$ \\
\hline
\end{tabular}


TABLE II

Mean Optimal Percentage Allocation to Stocks and Percentage Hedging Demand Over Myopic Demand (Sample: 1926.01 - 1997.12)

\begin{tabular}{ll}
\hline \hline R.R.A. & E.I.S. \\
\hline
\end{tabular}

(A) Mean optimal allocation to stocks (\%):

\begin{tabular}{rrrrrrrr}
\multicolumn{7}{c}{$\mathrm{E}\left[\pi_{t}\left(y_{t}\right)\right]=\pi(\theta) \times \mathbf{1 0 0}$} \\
& 1.00 & $1 / 1.5$ & $1 / 2$ & $1 / 4$ & $1 / 10$ & $1 / 20$ & $1 / 40$ \\
1.00 & 221.39 & 221.39 & 221.39 & 221.39 & 221.39 & 221.39 & 221.39 \\
1.50 & 145.93 & 145.95 & 145.95 & 145.97 & 145.97 & 145.98 & 145.98 \\
2.00 & 108.84 & 108.84 & 108.84 & 108.84 & 108.83 & 108.83 & 108.83 \\
4.00 & 53.98 & 53.96 & 53.94 & 53.92 & 53.91 & 53.90 & 53.90 \\
10.0 & 21.49 & 21.47 & 21.46 & 21.45 & 21.44 & 21.43 & 21.43 \\
20.0 & 10.73 & 10.72 & 10.71 & 10.70 & 10.70 & 10.69 & 10.69 \\
40.0 & 5.36 & 5.35 & 5.35 & 5.35 & 5.34 & 5.34 & 5.34
\end{tabular}

(B) Ratio of hedging demand over myopic demand (\%):

\begin{tabular}{rrrrrrrr} 
& 1.00 & $1 / 1.5$ & $1 / 2$ & $1 / 4$ & $1 / 10$ & $1 / 20$ & $1 / 40$ \\
1.00 & 0.00 & 0.00 & 0.00 & 0.00 & 0.00 & 0.00 & 0.00 \\
1.50 & -1.13 & -1.12 & -1.11 & -1.10 & -1.10 & -1.10 & -1.10 \\
2.00 & -1.67 & -1.68 & -1.68 & -1.68 & -1.68 & -1.68 & -1.68 \\
4.00 & -2.47 & -2.52 & -2.54 & -2.58 & -2.60 & -2.61 & -2.61 \\
10.0 & -2.93 & -3.02 & -3.06 & -3.13 & -3.18 & -3.19 & -3.20 \\
20.0 & -3.09 & -3.19 & -3.24 & -3.32 & -3.37 & -3.39 & -3.40 \\
40.0 & -3.16 & -3.27 & -3.33 & -3.42 & -3.47 & -3.49 & -3.50 \\
\hline
\end{tabular}


TABLE III

Mean Optimal Percentage Allocation to Stocks and Percentage Hedging Demand Over Myopic Demand (Sample: 1871 - 1997)

\begin{tabular}{ll}
\hline \hline R.R.A. & E.I.S. \\
\hline
\end{tabular}

(A) Mean optimal allocation to stocks (\%):

\begin{tabular}{rrrrrrrr}
\multicolumn{7}{c}{$\mathrm{E}\left[\pi_{t}\left(y_{t}\right)\right]=\pi(\theta) \times \mathbf{1 0 0}$} \\
& 1.00 & $1 / 1.5$ & $1 / 2$ & $1 / 4$ & $1 / 10$ & $1 / 20$ & $1 / 40$ \\
1.00 & 208.33 & 208.33 & 208.33 & 208.33 & 208.33 & 208.33 & 208.33 \\
1.50 & 131.87 & 131.95 & 131.99 & 132.06 & 132.10 & 132.11 & 132.12 \\
2.00 & 96.79 & 96.60 & 96.49 & 96.32 & 96.21 & 96.17 & 96.15 \\
4.00 & 47.02 & 46.67 & 46.48 & 46.15 & 45.92 & 45.85 & 45.80 \\
10.0 & 18.52 & 18.31 & 18.20 & 18.00 & 17.87 & 17.82 & 17.80 \\
20.0 & 9.21 & 9.10 & 9.04 & 8.93 & 8.86 & 8.83 & 8.82 \\
40.0 & 4.59 & 4.54 & 4.50 & 4.45 & 4.41 & 4.40 & 4.39
\end{tabular}

(B) Ratio of hedging demand over myopic demand (\%):

\begin{tabular}{rrrrrrrr} 
& 1.00 & $1 / 1.5$ & $1 / 2$ & $1 / 4$ & $1 / 10$ & $1 / 20$ & $1 / 40$ \\
1.00 & 0.00 & 0.00 & 0.00 & 0.00 & 0.00 & 0.00 & 0.00 \\
1.50 & -5.05 & -4.99 & -4.96 & -4.91 & -4.89 & -4.88 & -4.87 \\
2.00 & -7.08 & -7.27 & -7.37 & -7.53 & -7.64 & -7.68 & -7.69 \\
4.00 & -9.72 & -10.38 & -10.76 & -11.40 & -11.82 & -11.98 & -12.06 \\
10.0 & -11.12 & -12.09 & -12.65 & -13.58 & -14.21 & -14.44 & -14.56 \\
20.0 & -11.57 & -12.64 & -13.25 & -14.28 & -14.97 & -15.22 & -15.35 \\
40.0 & -11.78 & -12.90 & -13.54 & -14.62 & -15.34 & -15.60 & -15.73 \\
\hline \hline
\end{tabular}




\section{TABLE IV}

Optimal Consumption-Wealth Ratio and Long-Term Expected Return on Wealth

(Sample: 1926.01 - 1997.12)

\begin{tabular}{|c|c|c|c|c|c|c|c|}
\hline R.R.A. & \multicolumn{7}{|c|}{ E.I.S. } \\
\hline & \multirow{2}{*}{\multicolumn{7}{|c|}{$\begin{array}{l}\text { (A) Consumption-Wealth ratio (\%): } \\
C_{t} / X_{t}=\exp \left\{E\left[c_{t}-x_{t}\right]\right\} \times 100\end{array}$}} \\
\hline & & & & & & & \\
\hline & 1.00 & $1 / 1.5$ & $1 / 2$ & $1 / 4$ & $1 / 10$ & $1 / 20$ & $1 / 40$ \\
\hline 1.00 & 6.00 & 7.45 & 8.17 & 9.26 & 9.91 & 10.13 & 10.24 \\
\hline 1.50 & 6.00 & 6.42 & 6.63 & 6.94 & 7.13 & 7.20 & 7.23 \\
\hline 2.00 & 6.00 & 5.92 & 5.88 & 5.82 & 5.79 & 5.78 & 5.77 \\
\hline 4.00 & 6.00 & 5.20 & 4.80 & 4.19 & 3.83 & 3.71 & 3.65 \\
\hline 10.0 & 6.00 & 4.78 & 4.16 & 3.24 & 2.69 & 2.51 & 2.42 \\
\hline 20.0 & 6.00 & 4.64 & 3.96 & 2.93 & 2.32 & 2.12 & 2.01 \\
\hline 40.0 & 6.00 & 4.57 & 3.85 & 2.78 & 2.13 & 1.92 & 1.81 \\
\hline \multicolumn{8}{|c|}{$\begin{array}{l}\text { (B) Long-Term expected return on wealth (\%): } \\
\qquad(\pi(\theta)(\mu-r)+r) \times 100\end{array}$} \\
\hline & 1.00 & $1 / 1.5$ & $1 / 2$ & $1 / 4$ & $1 / 10$ & $1 / 20$ & $1 / 40$ \\
\hline 1.00 & 19.19 & 19.19 & 19.19 & 19.19 & 19.19 & 19.19 & 19.19 \\
\hline 1.50 & 13.16 & 13.16 & 13.16 & 13.16 & 13.16 & 13.16 & 13.16 \\
\hline 2.00 & 10.20 & 10.20 & 10.20 & 10.20 & 10.20 & 10.20 & 10.20 \\
\hline 4.00 & 5.81 & 5.81 & 5.81 & 5.81 & 5.81 & 5.81 & 5.81 \\
\hline 10.0 & 3.22 & 3.22 & 3.21 & 3.21 & 3.21 & 3.21 & 3.21 \\
\hline 20.0 & 2.36 & 2.36 & 2.36 & 2.36 & 2.35 & 2.35 & 2.35 \\
\hline 40.0 & 1.93 & 1.93 & 1.93 & 1.93 & 1.93 & 1.93 & 1.93 \\
\hline
\end{tabular}


TABLE V

Volatility of the

Optimal Log Consumption-Wealth Ratio (\%)

(Sample: 1926.01 - 1997.12)

$$
-A \sigma \sqrt{ } \bar{\theta} \times 100
$$

\begin{tabular}{|c|c|c|c|c|c|c|c|}
\hline \multirow[t]{2}{*}{ R.R.A. } & \multicolumn{7}{|c|}{ E.I.S. } \\
\hline & 1.00 & $1 / 1.5$ & $1 / 2$ & $1 / 4$ & $1 / 10$ & $1 / 20$ & $1 / 40$ \\
\hline 1.00 & 0.00 & 0.88 & 1.29 & 1.89 & 2.24 & 2.35 & 2.40 \\
\hline 1.50 & 0.00 & 0.59 & 0.87 & 1.30 & 1.55 & 1.64 & 1.68 \\
\hline 2.00 & 0.00 & 0.44 & 0.66 & 0.99 & 1.19 & 1.26 & 1.29 \\
\hline 4.00 & 0.00 & 0.22 & 0.33 & 0.51 & 0.61 & 0.65 & 0.67 \\
\hline 10.0 & 0.00 & 0.09 & 0.13 & 0.21 & 0.25 & 0.26 & 0.27 \\
\hline 20.0 & 0.00 & 0.04 & 0.07 & 0.10 & 0.13 & 0.13 & 0.14 \\
\hline 40.0 & 0.00 & 0.02 & 0.03 & 0.05 & 0.06 & 0.07 & 0.07 \\
\hline
\end{tabular}




\section{TABLE VI}

Mean Optimal Percentage Allocation to Stocks When Expected Excess Returns Vary Linearly With Volatility

(Sample: 1926.01 - 1997.12)

$$
E_{t}\left[d S_{t} / S_{t}-r d t\right]=\alpha_{0}+\alpha_{1} v_{t}
$$

\begin{tabular}{llc}
\hline \hline R.R.A. & $\alpha_{1}$ \\
& \\
\hline
\end{tabular}

(A) Mean optimal allocation to stocks (\%):

$\begin{array}{rrrrrrrr} & -0.75 & -0.50 & -0.25 & 0.00 & 0.25 & 0.50 & 0.75 \\ 1.00 & 146.39 & 171.39 & 196.39 & 221.39 & 246.39 & 271.39 & 296.39 \\ 1.50 & 96.10 & 112.67 & 129.29 & 145.95 & 162.67 & 179.44 & 196.25 \\ 2.00 & 71.52 & 83.91 & 96.34 & 108.84 & 121.39 & 133.99 & 146.65 \\ 4.00 & 35.35 & 41.51 & 47.70 & 53.94 & 60.22 & 66.54 & 72.90 \\ 10.0 & 14.04 & 16.50 & 18.97 & 21.46 & 23.97 & 26.50 & 29.05 \\ 20.0 & 7.00 & 8.23 & 9.47 & 10.71 & 11.97 & 13.23 & 14.51 \\ 40.0 & 3.50 & 4.11 & 4.73 & 5.35 & 5.98 & 6.61 & 7.25\end{array}$

(B) Intercept of hedging demand (\%):

$\begin{array}{rrrrrrrr} & -0.75 & -0.50 & -0.25 & 0.00 & 0.25 & 0.50 & 0.75 \\ 1.00 & 0.00 & 0.00 & 0.00 & 0.00 & 0.00 & 0.00 & 0.00 \\ 1.50 & 0.21 & 0.09 & 0.02 & 0.00 & 0.02 & 0.09 & 0.19 \\ 2.00 & 0.23 & 0.10 & 0.03 & 0.00 & 0.03 & 0.10 & 0.22 \\ 4.00 & 0.18 & 0.08 & 0.02 & 0.00 & 0.02 & 0.08 & 0.18 \\ 10.0 & 0.08 & 0.04 & 0.01 & 0.00 & 0.01 & 0.04 & 0.09 \\ 20.0 & 0.04 & 0.02 & 0.01 & 0.00 & 0.01 & 0.02 & 0.05 \\ 40.0 & 0.02 & 0.01 & 0.00 & 0.00 & 0.00 & 0.01 & 0.02\end{array}$

(C) Slope of hedging demand times $\theta(\%)$ :

\begin{tabular}{rrrrrrrr} 
& -0.75 & -0.50 & -0.25 & 0.00 & 0.25 & 0.50 & 0.75 \\
1.00 & 0.00 & 0.00 & 0.00 & 0.00 & 0.00 & 0.00 & 0.00 \\
1.50 & -1.70 & -1.68 & -1.67 & -1.64 & -1.61 & -1.58 & -1.54 \\
2.00 & -1.91 & -1.89 & -1.88 & -1.86 & -1.83 & -1.81 & -1.77 \\
4.00 & -1.42 & -1.42 & -1.41 & -1.41 & -1.40 & -1.39 & -1.37 \\
10.0 & -0.68 & -0.68 & -0.68 & -0.68 & -0.68 & -0.67 & -0.67 \\
20.0 & -0.36 & -0.36 & -0.36 & -0.36 & -0.36 & -0.36 & -0.36 \\
40.0 & -0.18 & -0.18 & -0.18 & -0.18 & -0.18 & -0.18 & -0.18 \\
\hline
\end{tabular}




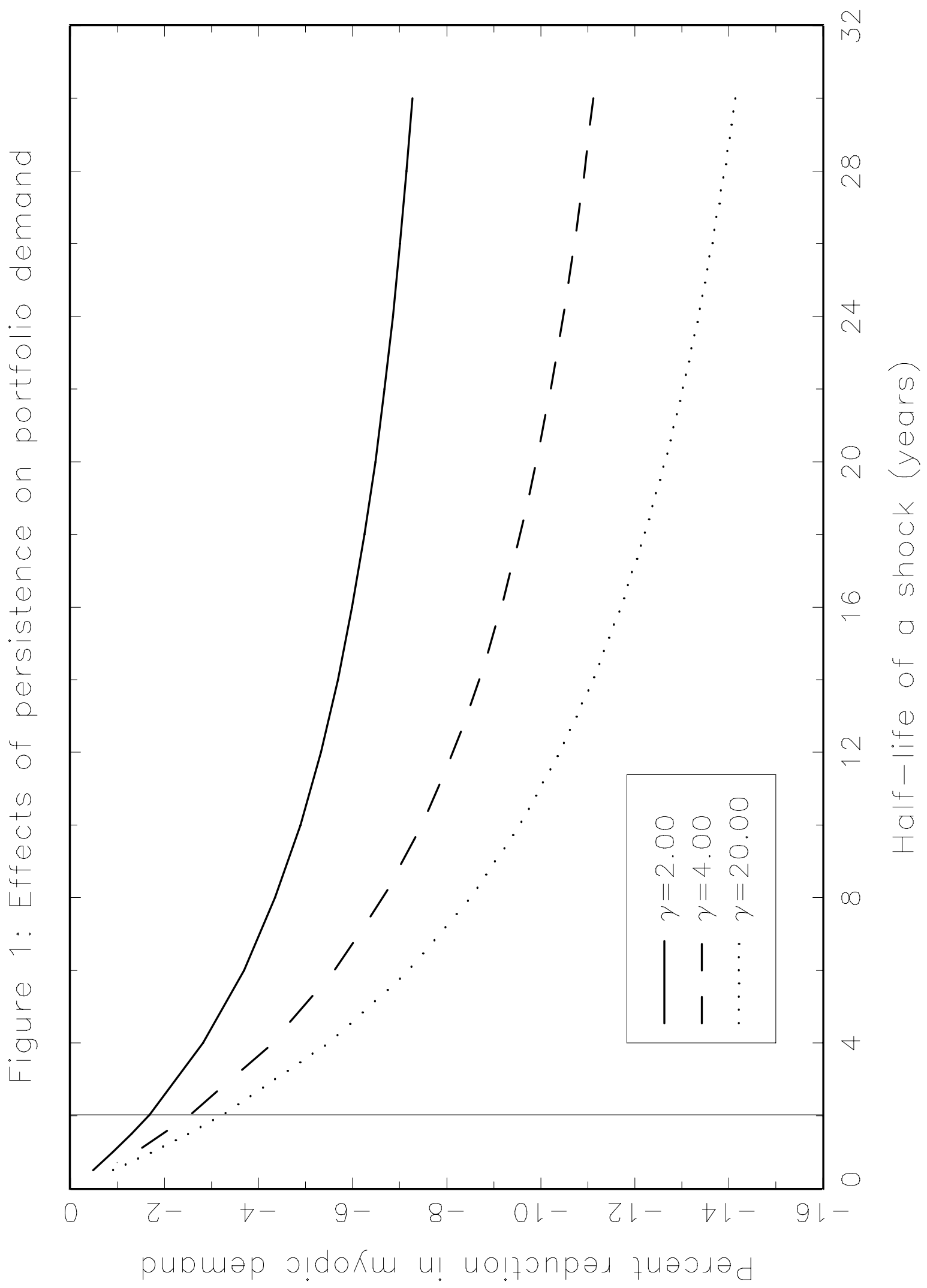




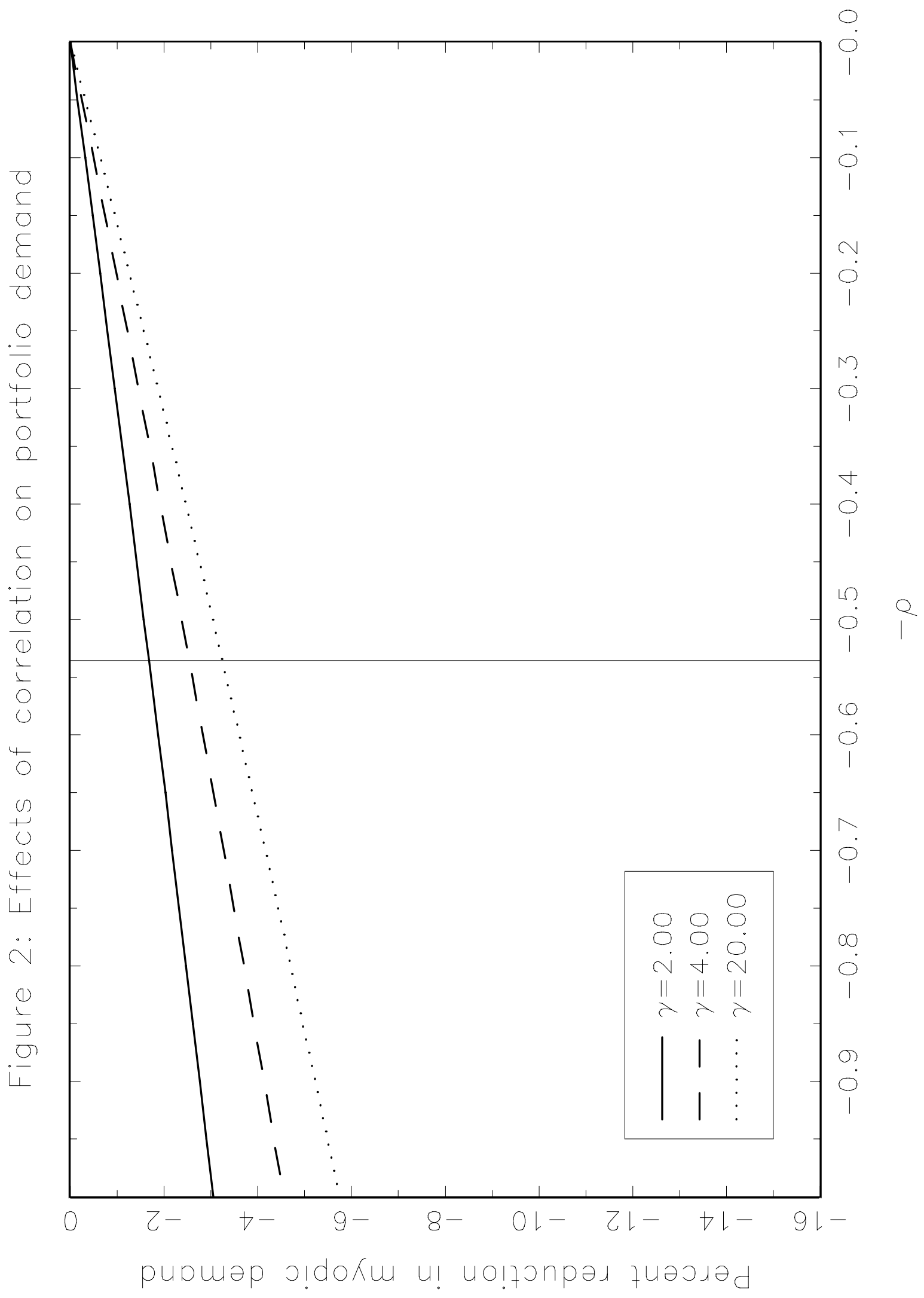


To order any of these papers in hard copy, see instructions at the end of this list. To subscribe to all NBER Working Papers or the papers in a single area, see instructions inside the back cover.

\begin{tabular}{|c|c|c|c|}
\hline Number & Author(s) & $\underline{\text { Title }}$ & \\
\hline 7323 & $\begin{array}{l}\text { Harry Holzer } \\
\text { David Neumark }\end{array}$ & Assessing Affirmative Action & $8 / 99$ \\
\hline 7324 & $\begin{array}{l}\text { Mark McClellan } \\
\text { Douglas Staiger }\end{array}$ & $\begin{array}{l}\text { Comparing Hospital Quality at For-Profit and Not-for- } \\
\text { Profit Hospitals }\end{array}$ & $8 / 99$ \\
\hline 7325 & $\begin{array}{l}\text { David Ikenberry } \\
\text { Josef Lakonishok } \\
\text { Theo Vermaelen }\end{array}$ & $\begin{array}{l}\text { Stock Repurchases in Canada: Performance and Strategic } \\
\text { Trading }\end{array}$ & $8 / 99$ \\
\hline 7326 & $\begin{array}{l}\text { Thomas C. Kinnaman } \\
\text { Don Fullerton }\end{array}$ & The Economics of Residential Solid Waste Management & $8 / 99$ \\
\hline 7327 & $\begin{array}{l}\text { Mark McClellan } \\
\text { Douglas Staiger }\end{array}$ & The Quality of Health Care Providers & $8 / 99$ \\
\hline 7328 & $\begin{array}{l}\text { John DiNardo } \\
\text { Mark P. Moore }\end{array}$ & $\begin{array}{l}\text { The Phillips Curve is Back? Using Panel Data to } \\
\text { Analyze the Relationship Between Unemployment and } \\
\text { Inflation in an Open Economy }\end{array}$ & $8 / 99$ \\
\hline 7329 & $\begin{array}{l}\text { Austan Goolsbee } \\
\text { Peter J. Klenow }\end{array}$ & $\begin{array}{l}\text { Evidence on Learning and Network Externalities in the } \\
\text { Diffusion of Home Computers }\end{array}$ & $9 / 99$ \\
\hline 7330 & $\begin{array}{l}\text { Young-Hye Cho } \\
\text { Robert F. Engle }\end{array}$ & $\begin{array}{l}\text { Time-Varying Betas and Asymmetric Effect of News: } \\
\text { Empirical Analysis of Blue Chip Stocks }\end{array}$ & 9/99 \\
\hline 7331 & $\begin{array}{l}\text { Young-Hye Cho } \\
\text { Robert F. Engle }\end{array}$ & $\begin{array}{l}\text { Modeling the Impacts of Market Activity on Bid-Ask } \\
\text { Spreads in the Option Market }\end{array}$ & $9 / 99$ \\
\hline 7332 & Daniel S. Hamermesh & The Changing Distribution of Job Satisfaction & $9 / 99$ \\
\hline 7333 & James L. Heckman & $\begin{array}{l}\text { Causal Parameters and Policy Analysis in Economics: } \\
\text { A Twentieth Century Retrospective }\end{array}$ & $9 / 99$ \\
\hline 7334 & $\begin{array}{l}\text { Rajesh K. Aggarwal } \\
\text { Andrew A. Samwick }\end{array}$ & $\begin{array}{l}\text { Performance Incentives Within Firms: The Effect of } \\
\text { Managerial Responsibility }\end{array}$ & $9 / 99$ \\
\hline 7335 & $\begin{array}{l}\text { Rajesh K. Aggarwal } \\
\text { Andrew A. Samwick }\end{array}$ & $\begin{array}{l}\text { Empire-Builders and Shirkers: Investment, Firm } \\
\text { Performance, and Managerial Incentives }\end{array}$ & $9 / 99$ \\
\hline 7336 & $\begin{array}{l}\text { Richard Portes } \\
\text { Hélène Rey }\end{array}$ & The Determinants of Cross-Border Equity Flows & $9 / 99$ \\
\hline 7337 & Kathryn M. Dominguez & The Market Microstructure of Central Bank Intervention & $9 / 99$ \\
\hline
\end{tabular}

You can download these and other papers at the NBER Web site:

www.nber.org

Free searchable abstracts are also available at the site. 
To order any of these papers in hard copy, see instructions at the end of this list. To subscribe to all NBER Working Papers or the papers in a single area, see instructions inside the back cover.

Number

7338

7339

7340

7341

7342

7343

7344

7345

7346

7347

7348

7349

7350

7351

7352
Author(s)

Jeffrey A. Frankel

Axel Börsch-Supan

Hylke Vandenbussche

Jozef Konings

Linda Springael

Robert F. Engle

Simone Manganelli

David C. King

Richard J. Zeckhauser

Christina Paxson

Jane Waldfogel

Michael Hout

Harvey S. Rosen

Jean O. Lanjouw

Mark Schankerman

Geert Bekaert

Steven R. Grenadier

Thomas N. Hubbard

Jonathan Gruber

Edward P. Lazear

Tamim Bayoumi

Taizo Motonishi

Hiroshi Yoshikawa

Daron Acemoglu

Robert Shimer $\underline{\text { Title }}$

$\underline{\text { Date }}$

No Single Currency Regime is Right for all Countries $\quad 9 / 99$ or at All Times

Incentive Effects of Social Security Under an Uncertain 9/99 Disability Option

Import Diversion under European Antidumping Policy

$9 / 99$

CAViaR: Conditional Value at Risk By Quantile Regression

$9 / 99$

Congressional Vote Options

$9 / 99$

Work, Welfare, and Child Maltreatment

$9 / 99$

Self-Employment, Family Background, and Race

$9 / 99$

The Quality of Ideas: Measuring Innovation with

Multiple Indicators

$9 / 99$

Stock and Bond Pricing in an Affine Economy

$9 / 99$

How Wide Is the Scope of Hold-Up-Based Theories?

$9 / 99$

Contractual Form and Market Thickness in Trucking

The Wealth of the Unemployed: Adequacy and

$9 / 99$

Implications for Unemployment Insurance

Educational Production

$9 / 99$

The Morning After: Explaining the Slowdown in Japanese Growth in the 1990s

Causes of the Long Stagnation of Japan during the

1990's: Financial or Real?

Productivity Gains From Unemployment Insurance

9/99

You can download these and other papers at the NBER Web site:

Free searchable abstracts are also available at the site. 
To order any of these papers in hard copy, see instructions at the end of this list. To subscribe to all NBER Working Papers or the papers in a single area, see instructions inside the back cover.

\begin{tabular}{|c|c|c|c|}
\hline Number & Author(s) & $\underline{\text { Title }}$ & \\
\hline 7353 & $\begin{array}{l}\text { Jeff Grogger } \\
\text { Charles Michalopoulos }\end{array}$ & Welfare Dynamics under Time Limits & $9 / 99$ \\
\hline 7354 & Roberto Rigobon & $\begin{array}{l}\text { On the Measurement of the International Propagation } \\
\text { of Shocks }\end{array}$ & $9 / 99$ \\
\hline 7355 & $\begin{array}{l}\text { Ricardo J. Caballero } \\
\text { Mohamad L. Hammour }\end{array}$ & $\begin{array}{l}\text { The Cost of Recessions Revisited: A Reverse- } \\
\text { Liquidationist View }\end{array}$ & 9/99 \\
\hline 7356 & $\begin{array}{l}\text { Alec Ian Gershberg } \\
\text { Michael Grossman } \\
\text { Fred Goldman }\end{array}$ & $\begin{array}{l}\text { Competition and the Cost of Capital Revisited: Special } \\
\text { Authorities and Underwriters in the Market for Tax- } \\
\text { exempt Hospital Bonds }\end{array}$ & $9 / 99$ \\
\hline 7357 & Robert E. Lipsey & $\begin{array}{l}\text { Foreign Production by U.S. Firms and Parent Firm } \\
\text { Employment }\end{array}$ & $9 / 99$ \\
\hline 7358 & Vernon Henderson & Marshall's Economies & $9 / 99$ \\
\hline 7359 & $\begin{array}{l}\text { Iain Cockburn } \\
\text { Rebecca Henderson } \\
\text { Scott Stern }\end{array}$ & $\begin{array}{l}\text { The Diffusion of Science-Driven Drug Discovery: } \\
\text { Organizational Change in Pharmaceutical Research }\end{array}$ & $9 / 99$ \\
\hline 7360 & $\begin{array}{l}\text { Douglas Holtz-Eakin } \\
\text { John W. Phillips } \\
\text { Harvey S. Rosen }\end{array}$ & Estate Taxes, Life Insurance, and Small Business & $9 / 99$ \\
\hline 7361 & $\begin{array}{l}\text { Bong-Chan Kho } \\
\text { René M. Stulz }\end{array}$ & Banks, the IMF, and the Asian Crisis & 9/99 \\
\hline 7362 & $\begin{array}{l}\text { Jagadeesh Gokhale } \\
\text { Laurence J. Kotlikoff }\end{array}$ & $\begin{array}{l}\text { Social Security's Treatment of Postwar Americans: } \\
\text { How Bad Can It Get? }\end{array}$ & $9 / 99$ \\
\hline 7363 & $\begin{array}{l}\text { Bruce D. Meyer } \\
\text { Dan T. Rosenbaum }\end{array}$ & $\begin{array}{l}\text { Welfare, the Earned Income Tax Credit, and the } \\
\text { Labor Supply of Single Mothers }\end{array}$ & $9 / 99$ \\
\hline 7364 & $\begin{array}{l}\text { Dani Rodrik } \\
\text { Andrés Velasco }\end{array}$ & Short-Term Capital Flows & $9 / 99$ \\
\hline 7365 & $\begin{array}{l}\text { Michael D. Bordo } \\
\text { Lars Jonung }\end{array}$ & $\begin{array}{l}\text { The Future of EMU: What Does the History of } \\
\text { Monetary Unions Tell Us? }\end{array}$ & $9 / 99$ \\
\hline 7366 & Emmanuel Saez & Do Taxpayers Bunch at Kink Points? & $9 / 99$ \\
\hline 7367 & Emmanuel Saez & $\begin{array}{l}\text { The Effect of Marginal Tax Rates on Income: A Panel } \\
\text { Study of 'Bracket Creep' }\end{array}$ & $9 / 99$ \\
\hline
\end{tabular}

You can download these and other papers at the NBER Web site:

www.nber.org

Free searchable abstracts are also available at the site. 
To order any of these papers in hard copy, see instructions at the end of this list. To subscribe to all NBER Working Papers or the papers in a single area, see instructions inside the back cover

\begin{tabular}{|c|c|}
\hline Number & Author(s) \\
\hline 7368 & $\begin{array}{l}\text { Alan L. Gustman } \\
\text { Thomas L. Steinmeier }\end{array}$ \\
\hline 7369 & $\begin{array}{l}\text { Wolfgang Keller } \\
\text { Arik Levinson }\end{array}$ \\
\hline 7370 & $\begin{array}{l}\text { Michael Baker } \\
\text { Gary Solon }\end{array}$ \\
\hline 7371 & $\begin{array}{l}\text { Michael Baker } \\
\text { Nicole M. Fortin }\end{array}$ \\
\hline 7372 & $\begin{array}{l}\text { B. Douglas Bernheim } \\
\text { Lorenzo Forni } \\
\text { Jagadeesh Gokhale } \\
\text { Laurence J. Kotlikoff }\end{array}$ \\
\hline 7373 & $\begin{array}{l}\text { Paul A. David } \\
\text { Bronwyn H. Hall } \\
\text { Andrew A. Toole }\end{array}$ \\
\hline 7374 & $\begin{array}{l}\text { Peter Cappelli } \\
\text { David Neumark }\end{array}$ \\
\hline 7375 & Charles I. Jones \\
\hline 7376 & $\begin{array}{l}\text { Harrison Hong } \\
\text { Jeremy C. Stein }\end{array}$ \\
\hline 7377 & $\begin{array}{l}\text { George Chacko } \\
\text { Luis M. Viceira }\end{array}$ \\
\hline
\end{tabular}

$\underline{\text { Title }}$

$\underline{\text { Date }}$

What People Don't Know About Their Pensions and Social Security: An Analysis Using Linked Data From The Health and Retirement Study

Environmental Compliance Costs and Foreign Direct

$9 / 99$ Investment Inflows to U.S. States

Earnings Dynamics and Inequality among Canadian Men, 1976-1992: Evidence from Longitudinal Income Tax Records

Occupational Gender Composition and Wages in Canada: 9/99 1987-1988

The Adequacy of Life Insurance: Evidence from the $10 / 99$ Health and Retirement Survey

Is Public R\&D a Complement or Substitute for Private $10 / 99$ R\&D? A Review of the Econometric Evidence

Do "High Performance" Work Practices Improve $10 / 99$ Established-Level Outcomes?

Was an Industrial Revolution Inevitable? Economic Growth Over the Very Long Run

Differences of Opinion, Rational Arbitrage and Market Crashes

Dynamic Consumption and Portfolio Choice with $10 / 99$ Stochastic Volatility in Incomplete Markets

Copies of the above working papers can be obtained for $\$ 10.00$ per copy (plus $\$ 10.00$ per order for shipping for all locations outside the continental U.S.) to Working Papers, NBER, 1050 Massachusetts Avenue, Cambridge, MA 02138-5398. Pre-payment is required on all orders and may be made by check or credit card. Checks should be made payable to the NBER and must be in dollars drawn on a U.S. bank. If paying by credit card, include the cardholder's name, account number, and expiration date. For all orders, please be sure to include your return address and telephone number. Working papers may also be ordered by telephone (868-3900), fax (617-868-2742), or email (orders(a)nber.org).

You can download these and other papers at the NBER Web site:

www.nber.org

Free searchable abstracts are also available at the site. 